Article

\title{
Integrated Electrical and Thermal Grid Facility - Testing of Future Microgrid Technologies
}

\author{
Sundar Raj Thangavelu ${ }^{\dagger}$, Inam Ullah Nutkani ${ }^{\dagger}$, Chia Meng Hwee ${ }^{\dagger}$, Aung Myat ${ }^{\dagger}$ and \\ Ashwin Khambadkone ${ }^{\dagger, *}$
}

Experimental Power Grid Centre, Institute of Chemical and Engineering Sciences, 3 Pesek Road, Singapore 627590, Singapore; E-Mails: sundar_thangavelu@epgc.a-star.edu.sg (S.R.T.); inam_nutkani@epgc.a-star.edu.sg (I.U.N.); chia_meng_hwee@epgc.a-star.edu.sg (C.M.H.); aung_myat@epgc.a-star.edu.sg (A.M.)

$\dagger$ These authors contributed equally to this work.

* Author to whom correspondence should be addressed; E-Mail: ashwinmk@epgc.a-star.edu.sg; Tel.: +65-6796-7386; Fax: +65-6316-6186.

Academic Editor: Josep M. Guerrero

Received: 15 July 2015 / Accepted: 6 September 2015 / Published: 16 September 2015

\begin{abstract}
This paper describes the Experimental Power Grid Centre (EPGC) microgrid test facility, which was developed to enable research, development and testing for a wide range of distributed generation and microgrid technologies. The EPGC microgrid facility comprises a integrated electrical and thermal grid with a flexible and configurable architecture, and includes various distributed energy resources and emulators, such as generators, renewable, energy storage technologies and programmable load banks. The integrated thermal grid provides an opportunity to harness waste heat produced by the generators for combined heat, power and cooling applications, and support research in optimization of combined electrical-thermal systems. Several case studies are presented to demonstrate the testing of different control and operation strategies for storage systems in grid-connected and islanded microgrids. One of the case studies also demonstrates an integrated thermal grid to convert waste heat to useful energy, which thus far resulted in a higher combined energy efficiency. Experiment results confirm that the facility enables testing and evaluation of grid technologies and practical problems that may not be apparent in a computer simulated environment.
\end{abstract}


Keywords: microgrid test facility; distributed generation; integrated electrical and thermal grids; flexible and configurable architecture; energy efficiency

\section{Introduction}

Distributed Generation (DG) is driving a paradigm shift in the traditional power system. The common approach for using DG is by forming a microgrid-A controllable entity consists of interconnected distributed energy resources (renewable, conventional combustion engine based generators and/or storage systems) and loads (electrical and thermal) that can balance its supply and demand locally, and can operate in islanded and/or grid-connected mode-which has emerged as a more viable solution to increase the power system efficiency, reliability and security [1,2]. The microgrids, being close to the load, increase overall efficiency of the system by saving towards transmission losses and waste heat recovery for heating or cooling applications.

Over the past decade, the microgrids have been demonstrated successfully for several technology configurations and applications, particularly in North America, Europe, and Asia [3-5]. According to a research report [6], the current (2Q2015) global installed microgrid capacity is estimated approximately $12 \mathrm{GW}$, out of which 47\% in Asia, 44\% in North America and 9\% in Europe. The widespread adoption of microgrids, however, is subject to overcoming of economic and institutional barriers. These barriers can be overcome by the reduction in the technology cost, offering proper incentives and utility tariff, and formation of the regulatory framework, including defining of grid interconnections and performance requirements and microgrid enabling market mechanism [7,8].

Considerable effort has already been made in defining the performance and interconnection requirements for the DG and microgrids. So far, the key development is the guideline standard for the DG, IEEE 1547 Series 1-3: Interconnecting Distributed Resources with Electric Power Systems [9] and for the microgrid, IEEE 1547.4: Guide for Design, Operation, and Integration of Distributed Resource Island Systems with Electric Power Systems [10]. These standards together with local grid codes have been widely adopted in the US. Similarly, the DG interconnection standards have been developed and adopted by the other countries, worth mentioning are Europe [11-13] and Japan [14-16]. The general outlines of the interconnection standards and local grid codes adopted by different countries are more or less similar; however, the specific performance parameters and test procedures have been tailored according to the local conditions and thus vary from country to country. The most important performance tests covered under these standards and codes are related to power quality, protection, fault ride through, grid synchronization, anti-islanding and reconnection. The future grid-codes are expected to include new tests and requirements such as active power curtailment, reactive power and voltage support, and low voltage (LV) and high voltage (HV) ride through capabilities [17,18]. In addition, future microgrid in industries and urban regions aims to improve energy efficiency to remain economical, one of the likely option is integrated thermal grid to recover waste heat from distributed generation into useful energy [19-21].

Each of the aforementioned performance tests for the DG and microgrids requires a flexible and specially designed experimentation facility. For the widespread adoption of microgrids, there is a need 
for such facilities that allow microgrid developers and service providers to test and validate their solutions against the local standards and codes before real deployment.

The Experimental Power Grid Centre (EPGC) has a unique microgrid test facility, rated at up to $1 \mathrm{MW}$, specially designed to perform a wide range of DG and microgrid tests, including those listed in the existing and being discussed in the upcoming standard and grid codes. Against a backdrop of rapid urbanization in the Asia Pacific region and national initiatives to make Singapore a Smart Nation and improve its status as a role model for sustainability and liveability, the facility was developed in line with EPGC's mission to work with industries, both local and international, research institutions and government organizations driving technological development in the field of new and advanced power systems.

This paper presents a design overview of the EPGC microgrid facility with integrated electrical and thermal grids, which allows test-bedding and research, development and demonstration (RD \& D) of a variety of DG and microgrid technologies. These technologies and solutions can be applied to a growing urban landscape where, for example, microgrids can be a solution for integrating more renewable and conventional technologies for remote applications of which an increasing number exist in the surrounding region. The paper further discusses a few cases of microgrid testing with the support of experimental results. The test cases elaborated in the subsequent sections of the paper are related to dynamic control of storage systems, microgrid islanding and reconnection, and microgrid frequency and voltage regulation using storage systems. A case study for heat recovery from the diesel generator exhaust is also presented, where the recovered heat energy is used to support air-conditioning in a tropical climate.

\section{Architecture of the Integrated Microgrid Facility at Experimental Power Grid Centre (EPGC)}

This section will highlight the features of EPGC facility comprising electrical grid and integrated thermal grids.

\subsection{Electrical Grid Architectures and Functionalities}

The EPGC microgrid topology is shown in the Figure 1. This facility has $400 \mathrm{~V} 4$ buses power network, each bus consists of 3 phase 4 wires. Buses can be operated independently or coupled to form various topologies ranging from radial, series, loop with the ability to vary bus impedances mimicking the distance between the buses. Figure 2 shows the picture of the actual bus panels.

Tables 1 and 2 shows the DG in EPGC microgrid comprising generators, emulators, photovolatic arrays, storage technologies and load banks [22,23]. At EPGC, three types of emulators are used for various experiments. Emulators are devices that mimic the behaviour of an actual machine; for example, a wind turbine emulator (WTE) allows us to input a wind velocity profile and the WTE will create the electrical power injection characteristics of a wind turbine generator connected to the experimental grid. Similarly for a photovoltaic (PV) emulator, it is able to inject DC power similar in character to a real PV array in various states of irradiance. The Power Grid emulator allows the creation of varying grid conditions to facilitate the study of the grid behaviour during different grid conditions without being connected to the power grid. Emulators provide the freedom from the geographical constraints of being 
located in Singapore. Wind profiles and irradiance profiles can be used to virtually transport the grid to various locations in the world. Furthermore, it provides repeatability when conducting experiments. In addition to the experimental grid, the researchers at EPGC also utilise various simulation and modelling platforms. Researchers can analyse various phenomenon in simulation before taking the next step in validating their models in the experimental grid.

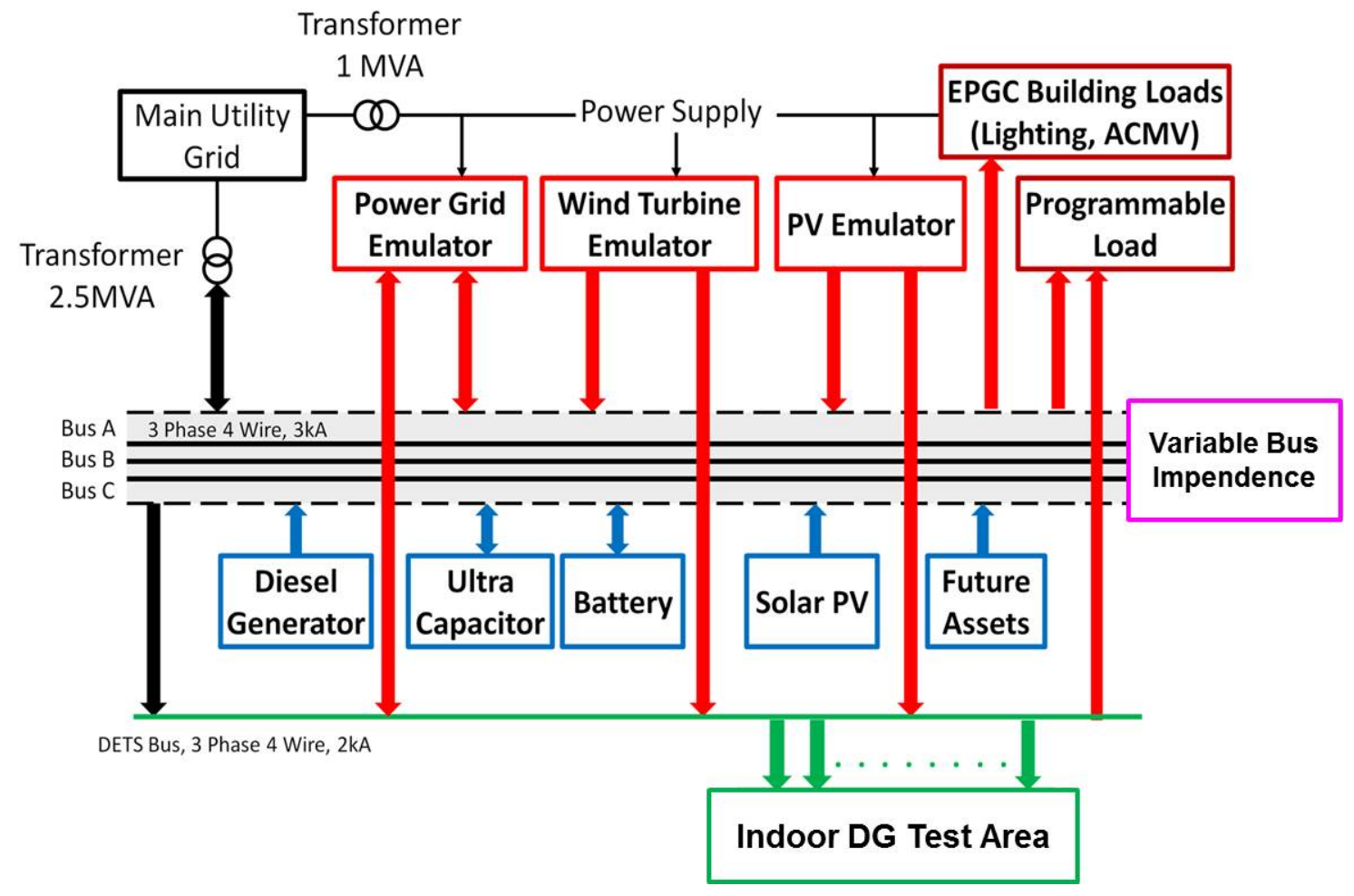

Figure 1. Schematic diagram of EPGC's microgrid facility.

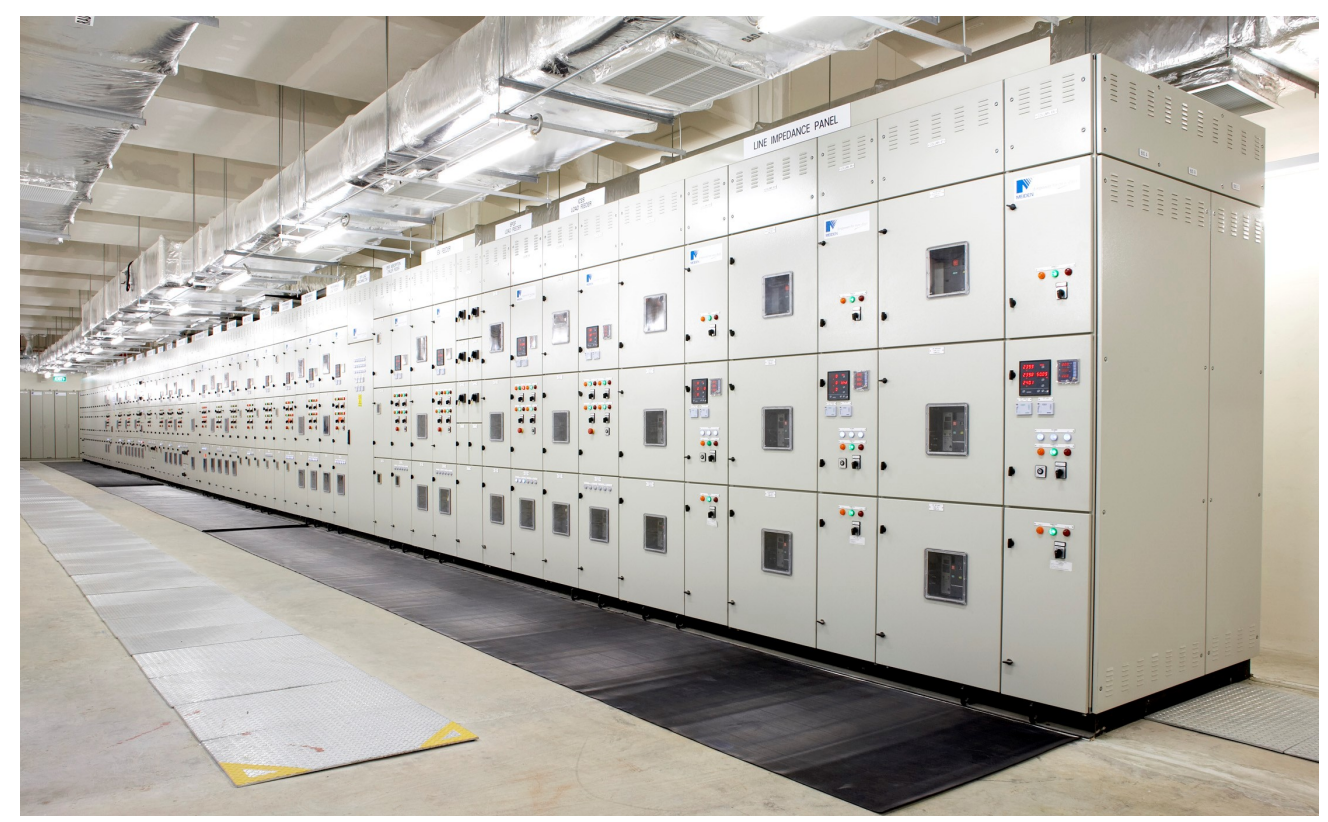

Figure 2. 3000 A, 400 V, 3 phase 4 wire Buses Panel. 
Table 1. Experimental grid assets.

\begin{tabular}{llll}
\hline Diesel Generators & Rating & Storage Technologies & Rating \\
\hline DG1 & $250 \mathrm{kVA}$ & Lithium Ion & $2 \times 20 \mathrm{kWh}$ \\
DG2 & $125 \mathrm{kVA}$ & Lead Acid & $110 \mathrm{kWh}$ \\
DG3 & $50 \mathrm{kVA}$ & Ultra-capacitors (Electric Double Layer Capacitor) & $90 \mathrm{~kW}$ for $30 \mathrm{~s}$ \\
& & & $60 \mathrm{~kW}$ for $30 \mathrm{~s}$ \\
\hline Photovoltaic Arrays & \multirow{2}{*}{ Rating } & Emulators & Rating \\
\hline Monocrystalline & $20 \mathrm{kWp}$ & Power Grid Emulator & $90 \mathrm{~kW}$ \\
Polycrystalline & $20 \mathrm{kWp}$ & Wind Turbine Emulator & $10 \mathrm{~kW}$ \\
Amorphous Thin Film & $20 \mathrm{kWp}$ & PV Array Emulator & $30 \mathrm{~kW}$ \\
\hline
\end{tabular}

Table 2. Programmable load banks.

\begin{tabular}{ccc}
\hline \multicolumn{3}{c}{ Rated Capacity } \\
\hline Resistive (kW) & Inductive (kVAR) & Capacitive (kVAR) \\
\hline 627 & 500 & 380 \\
\hline
\end{tabular}

\subsection{Thermal Grid Architectures and Functionalities}

The potential opportunity to improve the overall energy efficiency of the microgrid is in implementing the thermal grid to recover waste heat from the exhaust gas and convert into various useful forms of energy [20,24]. Figure 3 shows the thermal grid architecture which includes critical systems such as waste heat recovery system, absorption/adsorption chiller and thermal storage systems responsible for recovering waste energy and generating useful forms of thermal energy.

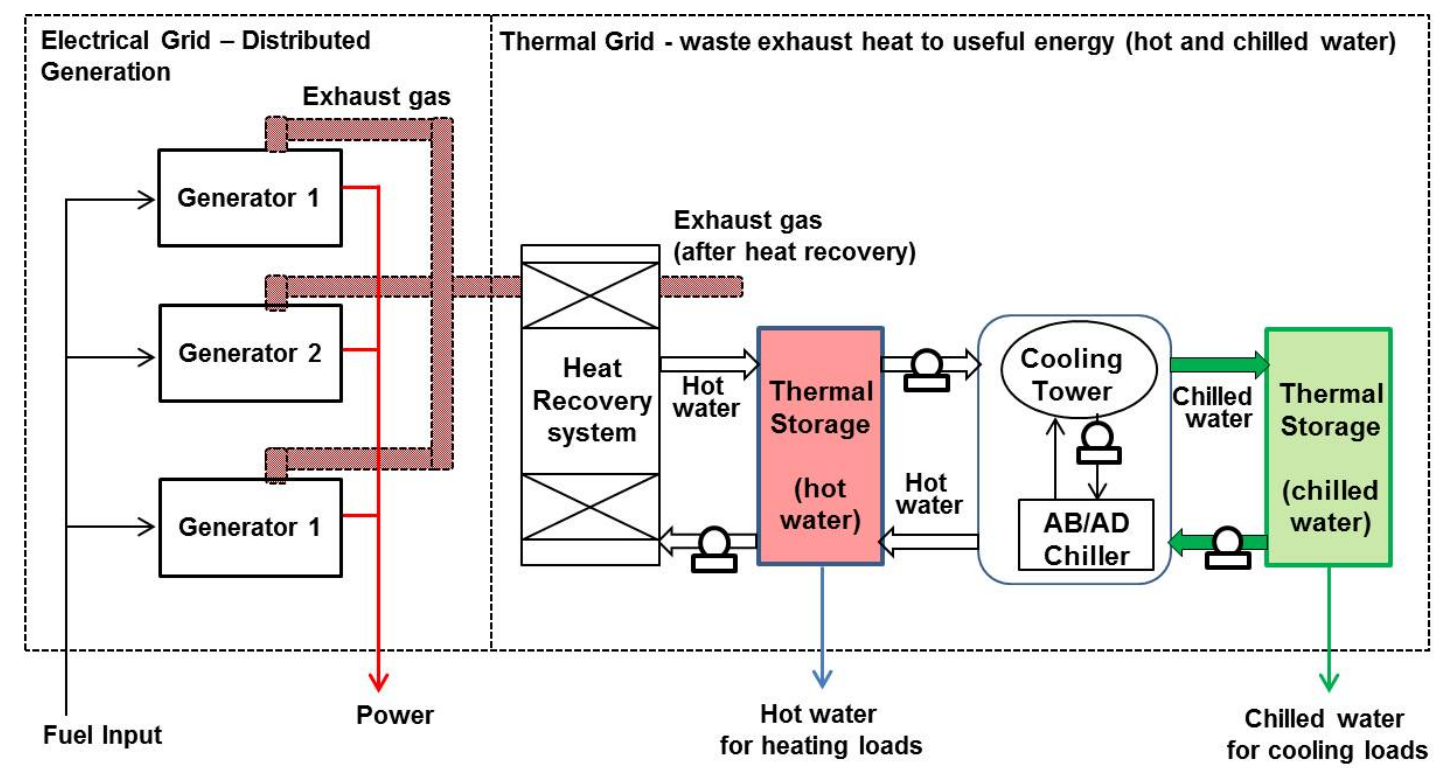

Figure 3. Thermal grid recovering waste heat into useful thermal energy. 


\subsubsection{Waste Heat Recovery System to Support Hot Thermal Loads}

The potential waste heat available in EPGC microgrid are from three generators $(50,125,250 \mathrm{kVA})$, load banks and solar-PV. A thermal grid is implemented and currently powered by the exhaust gas from generators to investigate the potential energy efficiency opportunities. Waste heat recovery system (WHRS) recovers waste heat in the form of steam or hot water depending on the heat potential of exhaust gas and the type of thermal loads [25]. A shell and tube heat exchanger is designed as WHRS based on the generator size and, the thermal and chemical properties of exhaust gas [26]. The designed WHRS recovers $55 \%-80 \%$ of heat from the exhaust gas, whereas the rest is rejected to the atmosphere considering the thermodynamic and design limits.

By implementing the WHRS system, the overall energy efficiency is increased from $\eta_{D E R}$ to $\eta_{D E R+W H R S}$ as shown in Equations (1)-(3),

$$
\begin{gathered}
\eta_{D E R+W H R S}=\frac{\text { useful energy }}{\text { fuel energy content }}=\frac{E_{\text {power }}+E_{\text {hot water }}}{E_{\text {fuel }}} \\
\eta_{D E R+W H R S}=\frac{E_{\text {power }}}{E_{\text {fuel }}}+\frac{E_{\text {fuel }}-E_{\text {power }}}{E_{\text {fuel }}} \frac{E_{\text {hot water }}}{E_{\text {fuel }}-E_{\text {power }}} \\
\eta_{D E R+W H R S}=\eta_{D E R}+\left(1-\eta_{D E R}\right) \eta_{W H R S}
\end{gathered}
$$

where, the combined energy efficiency $\left(\eta_{D E R+W H R S}\right)$ of diesel generator and waste heat recovery system is the ratio of useful energy (electrical energy $E_{\text {power }}$ and thermal energy $E_{\text {hot water }}$ ) to the energy content of the fuels $\left(E_{f u e l}\right) . \eta_{D E R}$ is the electrical efficiency of the diesel generator, which typically varies between $20 \%$ to $35 \%$, while operating at loads between $50 \%$ to $100 \%$ (full load condition). $\eta_{W H R S}$ is the efficiency of a waste heat recovery system which recovers heat energy from the exhaust gas to useful thermal energy such as hot water up to $90{ }^{\circ} \mathrm{C}$. The combined efficiency $\left(\eta_{D E R+W H R S}\right)$ ranges between $60 \%-74 \%$. Thermal grid with WHRS can support heating loads such as steam and hot water. The real benefits come when the heating loads locates near the WHRS otherwise the pumping cost need to be considered. When generated steam or hot water is higher than the heating loads, either thermal storage is a preferable option to store excess energy for later use or convert to other forms of useful energy such as chilled water depending on the cooling loads.

\subsubsection{Waste Heat Driven Absorption Chiller to Support Cold Thermal Loads}

The waste heat recovered in the form of steam or hot water is the main driver in the absorption system to produce chilled water. The refrigerant absorbs heat from chilled water (returning from air conditioning system) at a low temperature and pressure during evaporation, and release heat to the cooling water (to cooling tower) at a high temperature and pressure heat during condensation. The vaporised refrigerant (after evaporation) is absorbed into the absorbent at low pressure, followed by heating at high temperature to vaporize and restore its original concentration. Water and Lithium Bromide are the refrigerant and absorbent used in the absorption chiller. The recovered waste heat is used to vaporize the refrigerant for re-use. The performance of absorption chiller is represented as coefficient of performance (COP) or $\eta_{C H}$ that is the ratio of cooling capacity generated in the chilled 
water to the heat input i.e., heat supplied to the chiller as hot water. The overall energy efficiency of microgrid with integrated thermal grid is represented by $\eta_{D E R+W H R S+C H}$ (Equation (4)),

$$
\eta_{D E R+W H R S+C H}=\eta_{D E R}+\left(1-\eta_{D E R}\right) \eta_{W H R S} \eta_{C H}
$$

$\eta_{D E R+W H R S+C H}$ is the combined energy efficiency of diesel generator, waste heat recovery system and chiller describing the ratio of useful energy to the energy content of the fuels. The electrical efficiency of diesel generators (less than $250 \mathrm{KVA}$ ) at rated condition is $35 \%$, implementing the WHRS increases the combined energy efficiency to $74 \%$. In case of chilled water loads, the combined efficiency is $60 \%-85 \%$ depending on the absorption chiller type [27]. The COP or $\eta_{C H}$ of single effect absorption chiller is $0.65-0.8$ (for low temperature hot water driven), 0.7-0.75 for medium temperature hot water driven, and 0.7-0.75 for steam driven chillers. The COP or $\eta_{C H}$ of double effect absorption chiller is 1.4-1.45 (for high temperature hot water driven) and 1.38-1.43 for steam driven chiller whereas the triple effect absorption chiller (hot water or steam) achieves $\eta_{C H}$ to 1.8 [28,29]. This facility is installed with a 10 refrigeration ton of single effect absorption chiller driven by low temperature hot water at $90{ }^{\circ} \mathrm{C}$ to generate chilled water at $7^{\circ} \mathrm{C}$.

\subsubsection{Hot and Cold Thermal Storage System}

Thermal storage is cheaper than electrical storage and the energy cost is dominated by the operation cost unlike the capital cost and lifecycles of electrical storage system. The key purpose of thermal storage is to act as a buffer during the thermal supply and demand mismatch [24]. The thermal capacity of the storage system is effectively utilized by charging excess energy to use for peak shaving and peak shifting operations. Optimizing the storage temperature and advancing to phase-change-material (PCM) based storage are the possible options to increase storage capacity without changing the footprint area. Figure 4 shows the configuration of four cubic meter $\left(2 \times 2 \times 1 \mathrm{~m}^{3}\right)$ hot and cold thermal storage designed based on the WHRS, chiller system and air conditioning loads. The designed thermal storage can support the hot water and chilled water supply up to $1 \mathrm{~h}$ when DGs, WHRS and chiller not in operation.

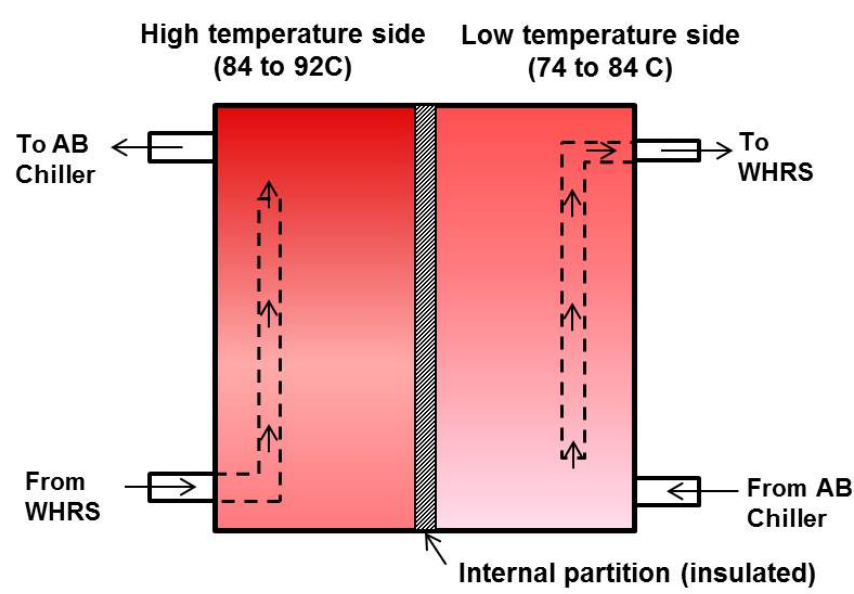

Hot Thermal Storage

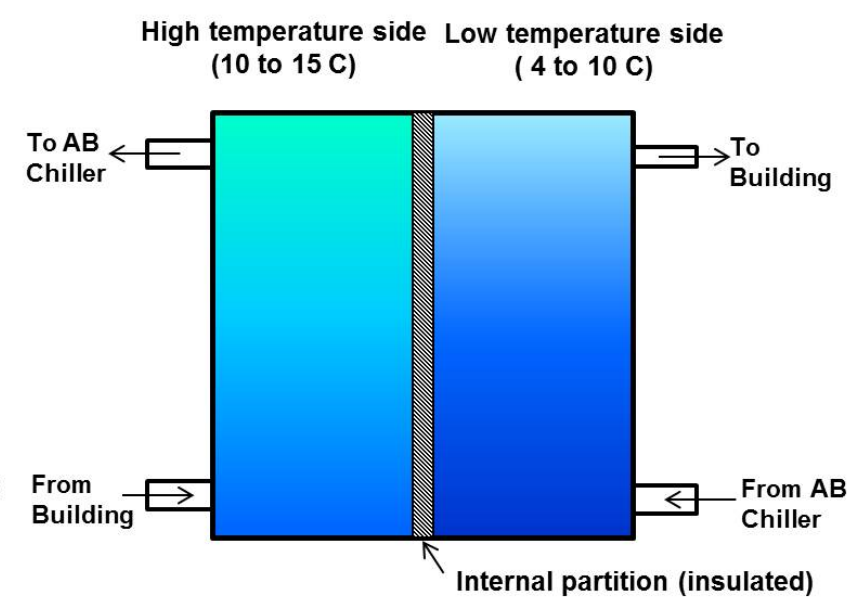

Cold Thermal Storage

Figure 4. Schematic configuration of hot and cold thermal storage. 


\section{Experimental Case Studies}

This section discuss the experimental case studies investigating the control aspects of different microgrid topologies and the potential of optimized control to improve the overall energy efficiency of microgrid.

\subsection{Coordinated Control of Hybrid Storage System in Grid-Connected Microgrid}

By definition, microgrid is a single controllable entity that can balance its supply and demand locally without causing any disturbance to the utility grid. For the planning and designing of such microgrids and its control, EPGC experimental facility can be used to test and evaluate the performance of different microgrids configurations and control algorithms. Test case in this section demonstrates dynamic coordinated control of two different types of storage systems operating in the microgrid. During the transients, the considered microgrid can balance its supply and demand without causing any disturbance to the utility grid. As shown in Figure 5a, the microgrid comprises Diesel Generator (DG2), Electric Double-Layer Capacitor (EDLC1), and Programmable Load Bank (PLB2), where power flow control at Point of Common Coupling (PCC) is set equal to zero.

The experimental results for two different cases of load change in the microgrid are shown in Figure 6. The control mode for EDLC1 is set to 'local follow' as shown in Figure 5b and LeadAcid is set to "local follow" and "with EDLC" in order to compensate the rapid change in power at PCC, as shown in Figure 5b,c. This coordinated control behavior can be witnessed from the experimental results shown in Figure 6, where EDLC1 promptly responds to the load change at 25:24 s by charging $50 \mathrm{~kW}$ power for a short duration. At the same time, LeadAcid storage also responds to the load change, but at the slower rate than EDLC1, which is for obvious reasons. This coordinated dynamic control of two different storage systems allows DG2 to ramp down according to its design characteristics without causing any sudden power fluctuation at the PCC, which is the main objective of this control strategy.

\subsection{Microgrid Islanding and Reconnection with Utility Grid}

Another desired feature of the practical microgrid is to operate in islanded and grid-connected mode. According to standard 1547, the grid-connected DGs and microgrid shall transition from grid-connected to islanded mode during the grid disturbance and re-connect back once the grid is normal, within specified time duration. This transition shall be smooth such that the islanded microgrid shall continue to balance its supply and demand. EPGC facility is designed to perform anti-islanding tests for the DG and microgrids according to the standard IEEE 1547 . This case study demonstrates an example of smooth transition from grid-connected mode to islanded-mode and vice versa, for the configured microgrid shown in Figure 7. The experimental results for the microgrid islanding and reconnection are shown in Figure 8. At operating point 1, the microgrid transitions into islanded mode while it is importing contracted power of $40 \mathrm{~kW}$ from the utility grid named as "Singapore Power PowerGrid (SPPG)". The power imbalance due to islanding is compensated by DG2 followed by LeadAcid which is operating in local follow mode. 
At operating point 2, the microgrid is commanded to re-connect and synchronize with the utility grid (i.e., SPPG) to continue importing the contracted power of $40 \mathrm{~kW}$. As shown from the experimental results in Figure 8, the transition from islanded-mode to grid-connected mode is very smooth, where LeadAcid plays an important role to maintain the steady ramp-rate at PCC point whereby allowing DG2 to ramp down according to its characteristics.

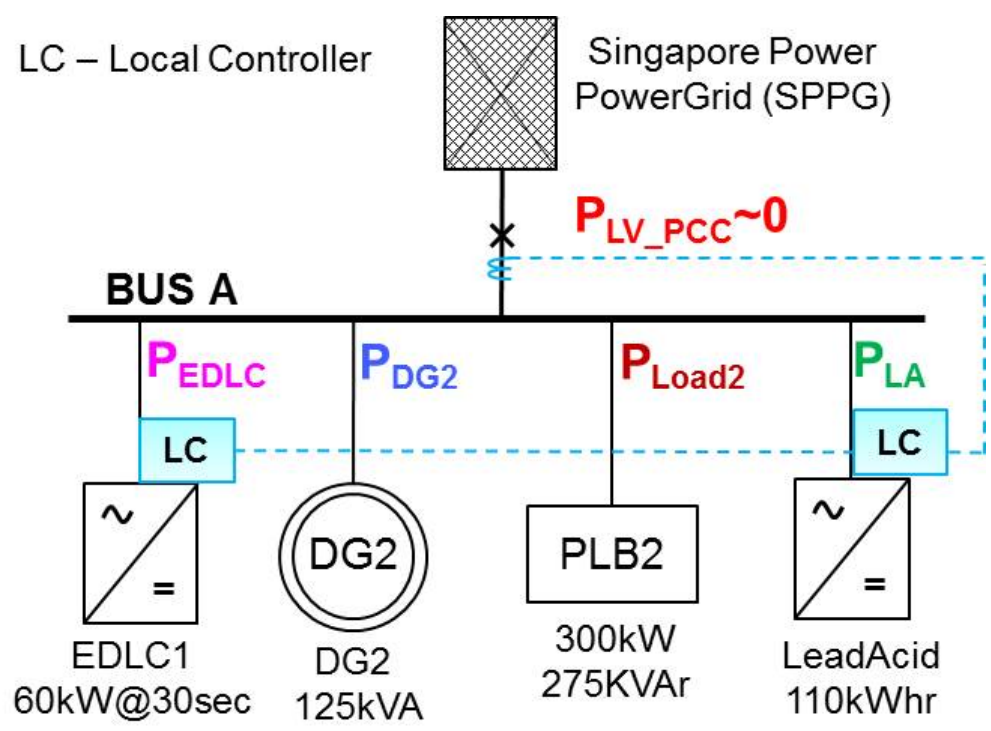

(a)

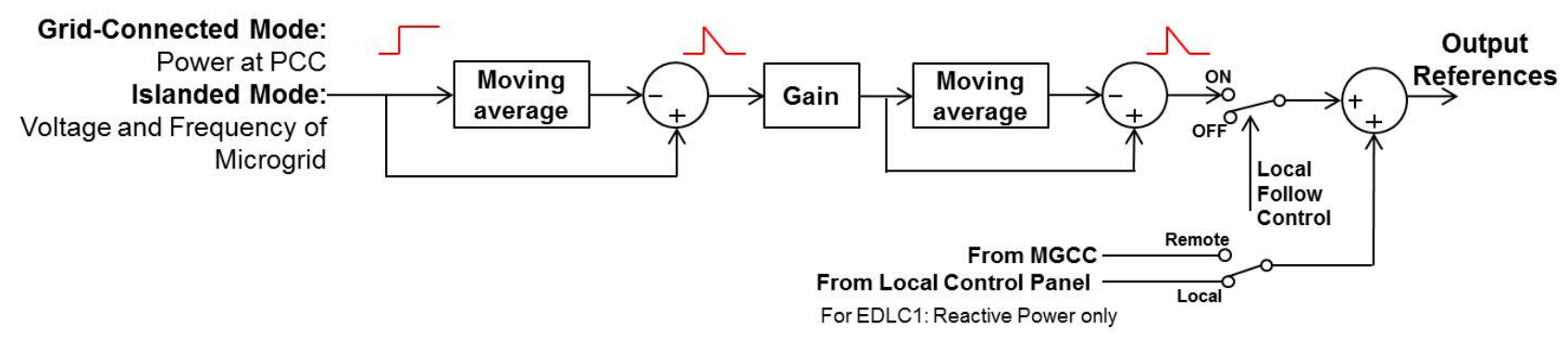

(b)

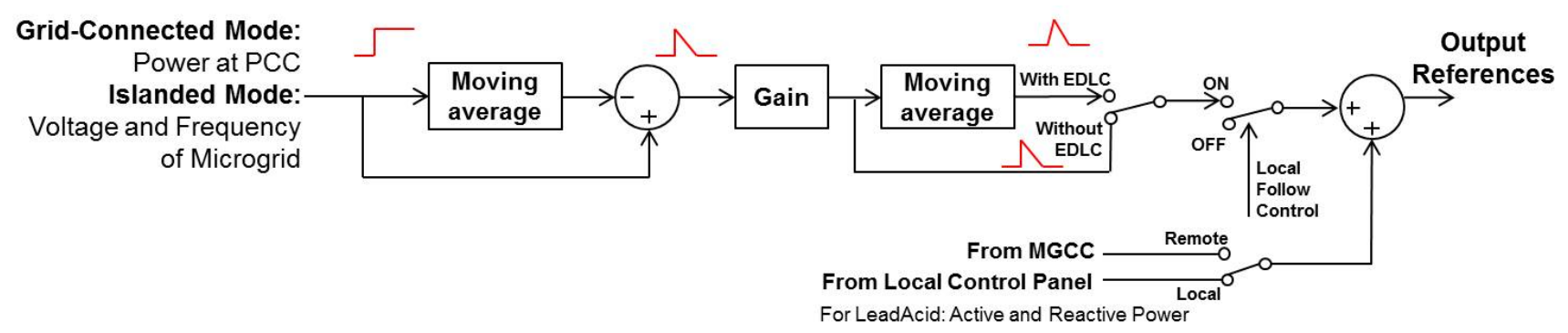

(c)

Figure 5. Microgrid configuration and control schemes during grid-connected and islanded mode operation. (a) Configured microgrid for storage control test; (b) Control scheme for EDLC1; (c) Control scheme for LeadAcid storage. 


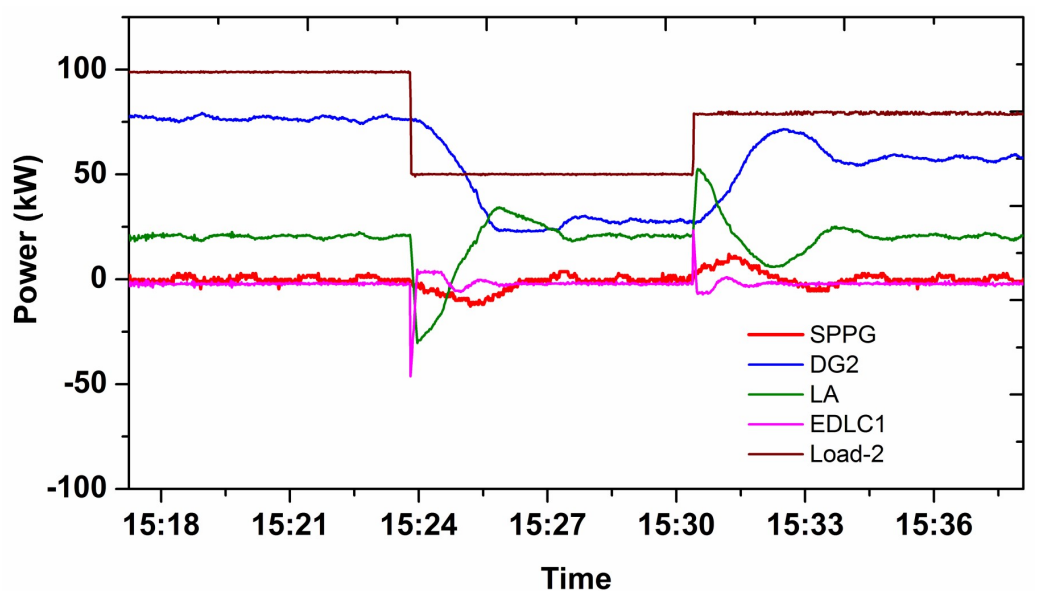

Figure 6. Experimental results showing EDLC1 and LeadAcid coordinated control to maintain PCC power 0 during sudden load change in microgrid.

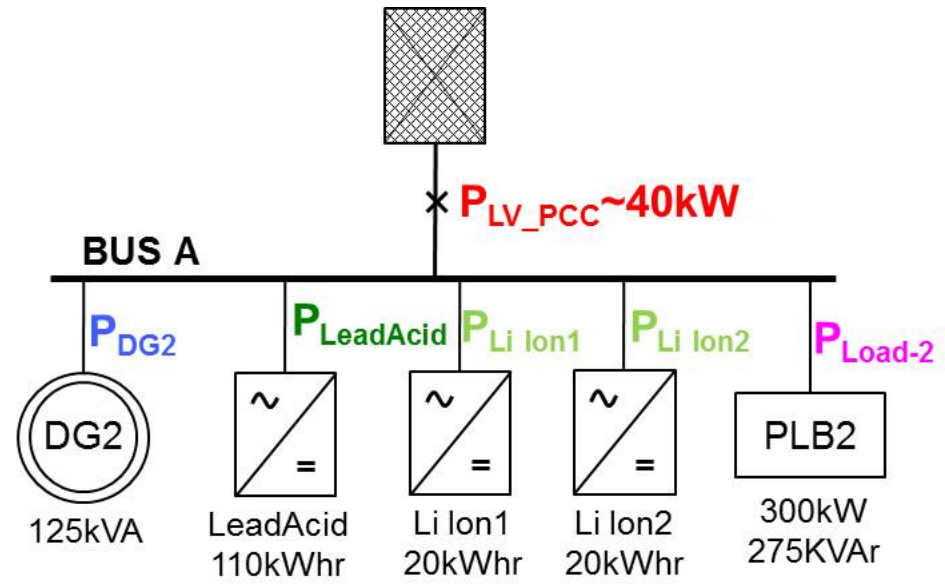

Figure 7. Configured microgrid for islanding and reconnection test.

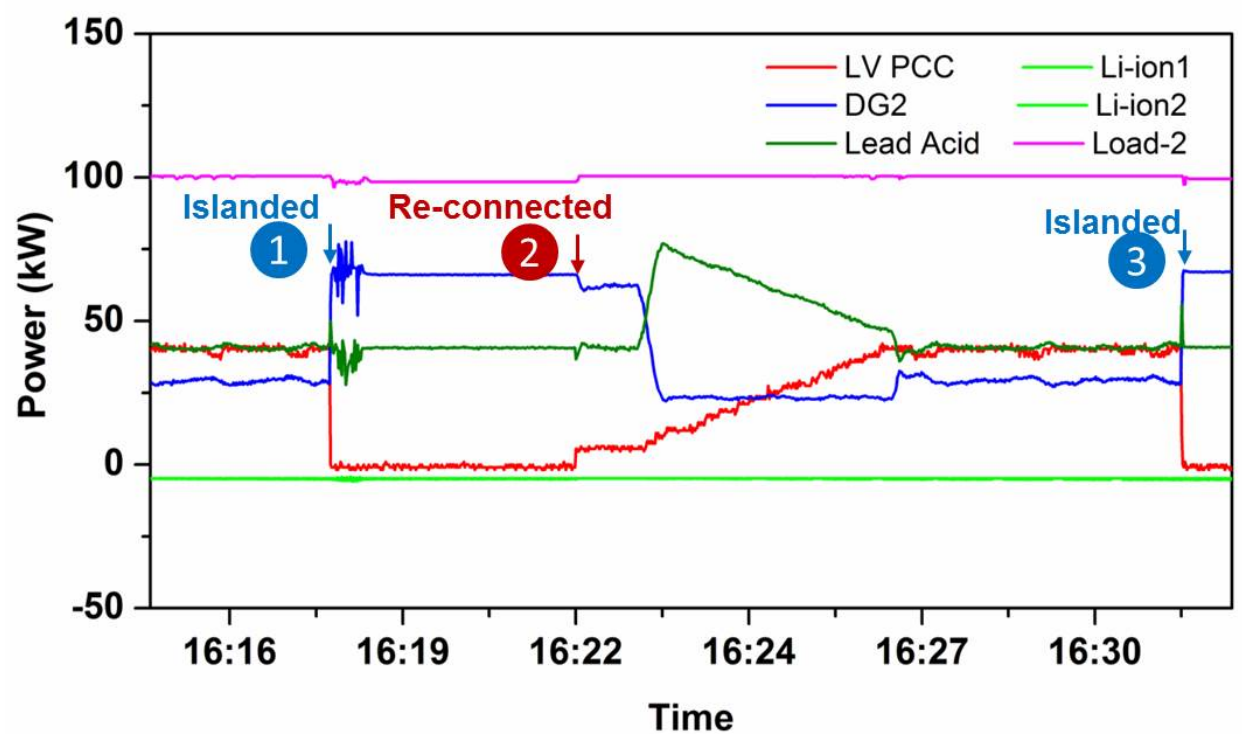

Figure 8. Experimental results showing microgrid islanding and reconnection with utility grid while importing $40 \mathrm{~kW}$ during grid-connected mode. 


\subsection{Storage Application for Frequency and Voltage Regulation in Microgrid}

In this case, the islanded microgrid shown in Figure 9 is tested with and without energy storage. The fast response energy storage system plays important role in maintaining the power quality in the low inertia microgrids, which has been demonstrated through this test case. The test results demonstrate that the frequency and voltage of low inertia microgrid can be regulated with proper control of storage system. The control scheme for LeadAcid and EDLC1 is shown in Figure 5b,c. With the common objective to improve the voltage and frequency variation during the load change (up and down), three different scenarios are tested as briefly described below,

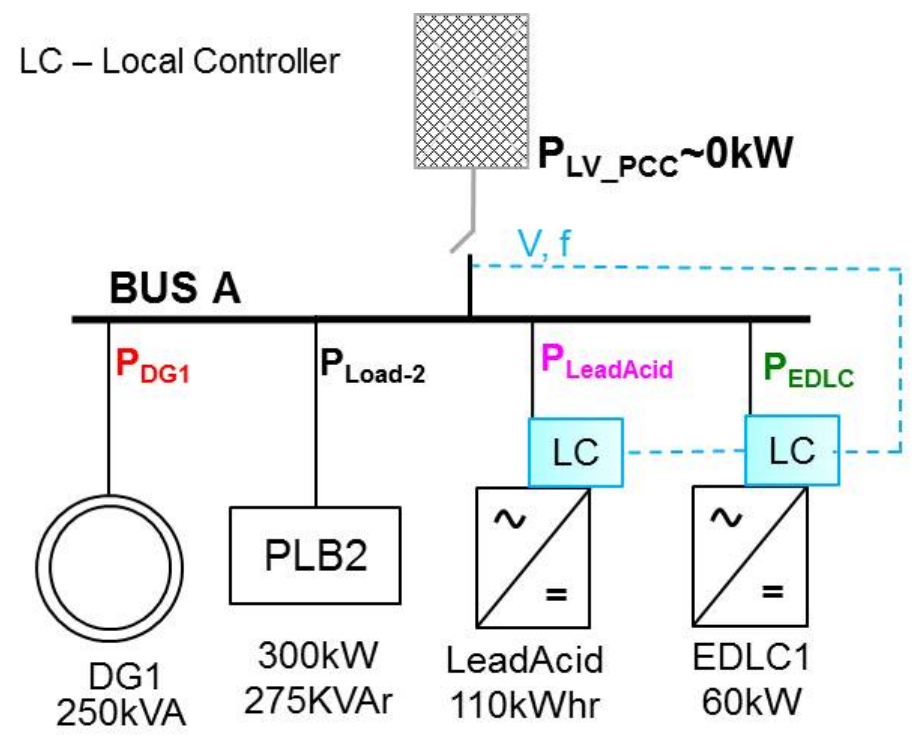

Figure 9. Configured islanded microgrid for storage application test.

Scenario 1: LeadAcid only responds to the frequency and voltage change according to the control scheme shown in Figure 5c.

Scenario 2: EDLC1 only responds to the frequency and voltage change according to the control scheme shown in Figure $5 b$.

Scenario 3: Both EDLC1 and LeadAcid respond to the frequency and voltage change, as shown in Figure 5b,c. In this case, EDLC and LeadAcid response is coordinated, where ELDC lead by providing the faster response and LeadAcid provide slow response while "without EDLC" mode is activated, as shown in Figure 5c.

The experimental results for the microgrid frequency and voltage variation during the step load change (up and down) are shown from Figures 10-13 and summarized in Table 3.

As shown in Figure 10, the microgrid frequency varies from 50 to $45.77 \mathrm{~Hz}(8.5 \%)$ and voltage varies from 410 to $347 \mathrm{~V}(15 \%)$ when load changes from $50 \mathrm{~kW}, 0 \mathrm{kVAr}$ to $150 \mathrm{~kW}, 50 \mathrm{kVAr}$ during DG2 operation only. The same load change test is then repeated after activating the LeadAcid (LA) storage local follow control, which shows significant improvement in the microgrid frequency and voltage. With DG2 and LA storage, the microgrid frequency varies from 50 to $48.97 \mathrm{~Hz}(2 \%)$ and voltage varies from 410 to $395 \mathrm{~V}(3.5 \%)$, which is significantly better than without storage. Similarly, the experimental 
results for the load step-down test also demonstrate the frequency and voltage regulation in the microgrid when storage system local follow control is activated.

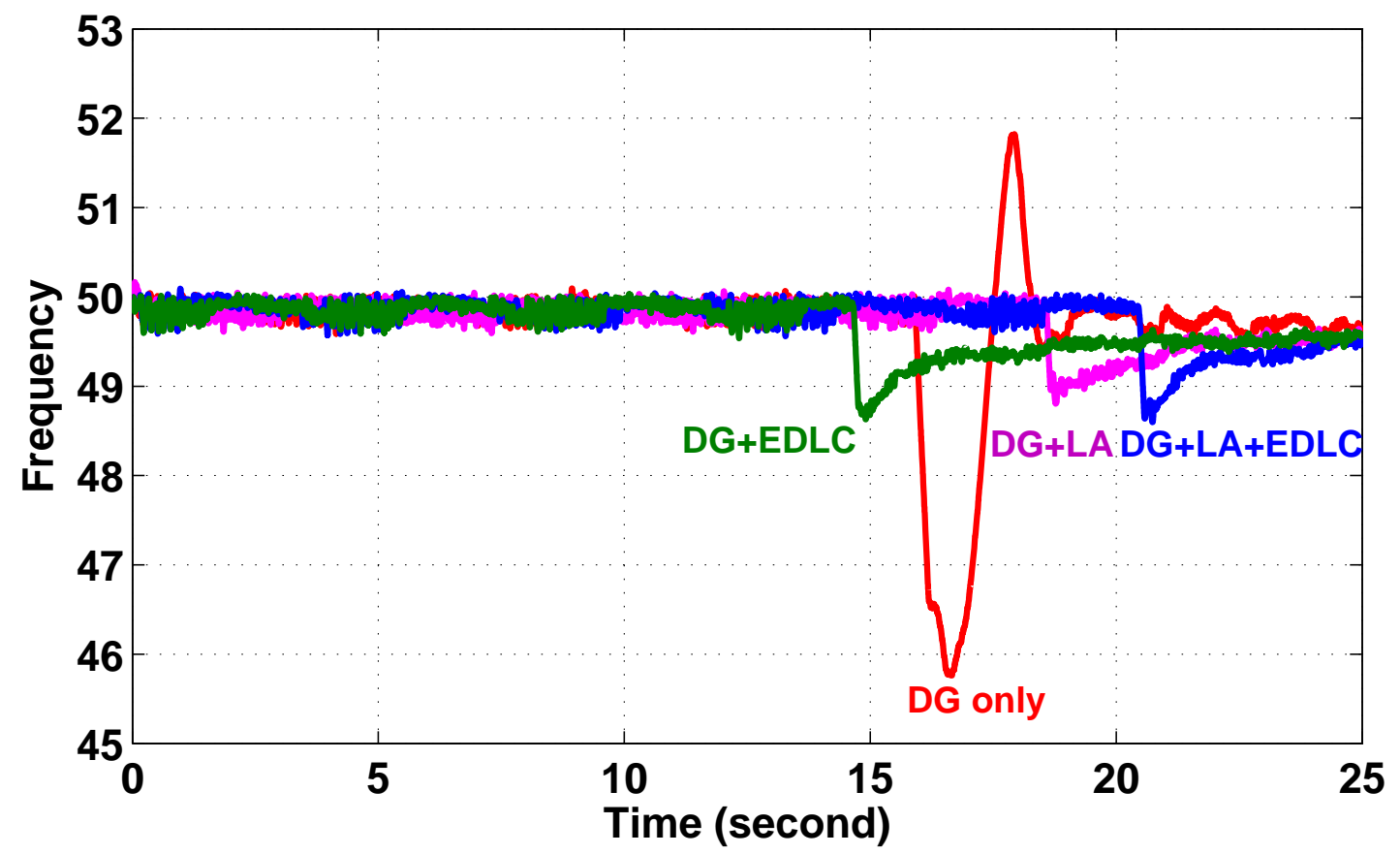

Figure 10. Experimental result showing microgrid frequency with and without storage during load step up from $50 \mathrm{~kW}, 0 \mathrm{kVAr}$ to $150 \mathrm{~kW}, 50 \mathrm{kVAr}$.

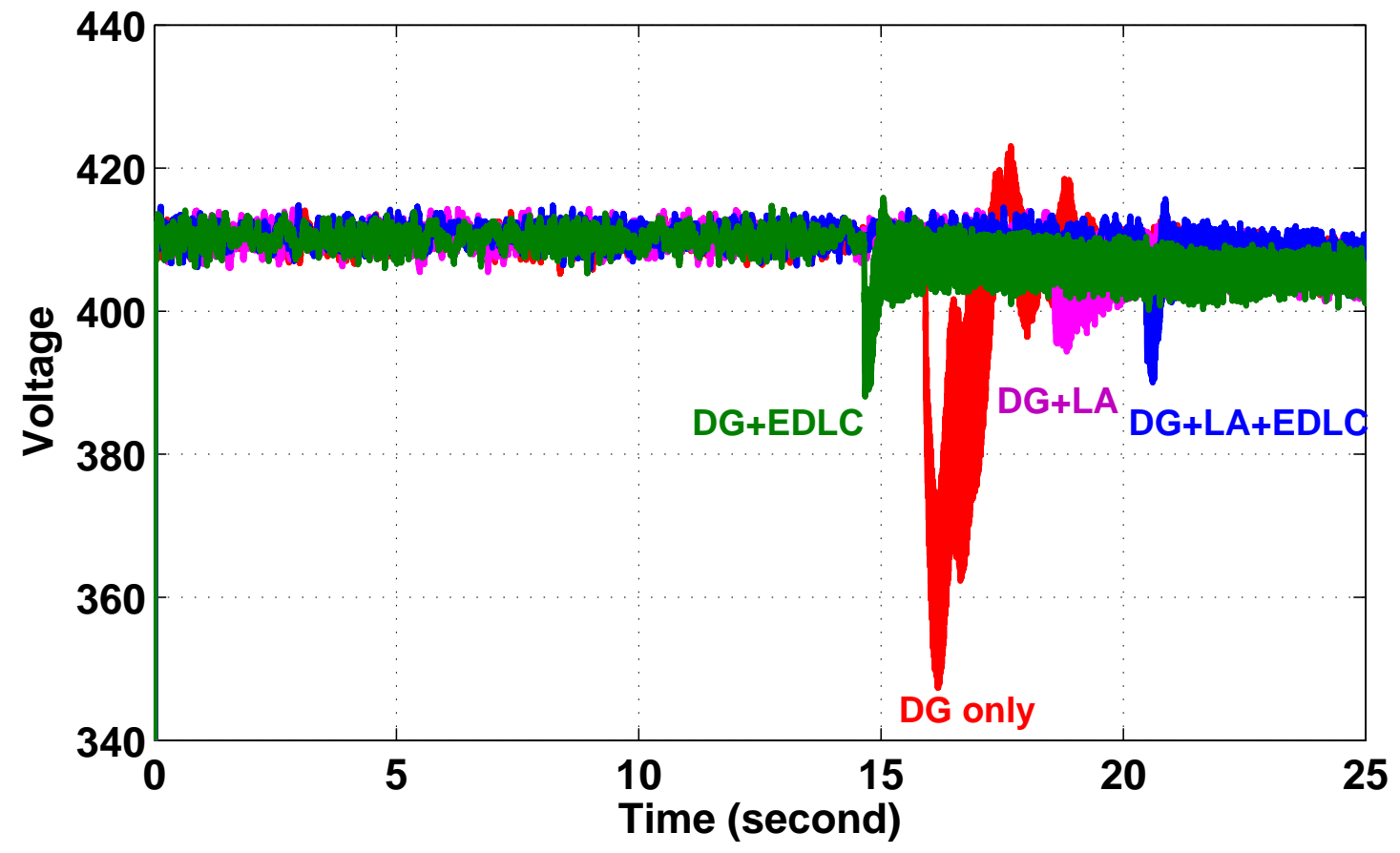

Figure 11. Experimental result showing microgrid voltage with and without storage during load step up from $50 \mathrm{~kW}, 0 \mathrm{kVAr}$ to $150 \mathrm{~kW}, 50 \mathrm{kVAr}$. 


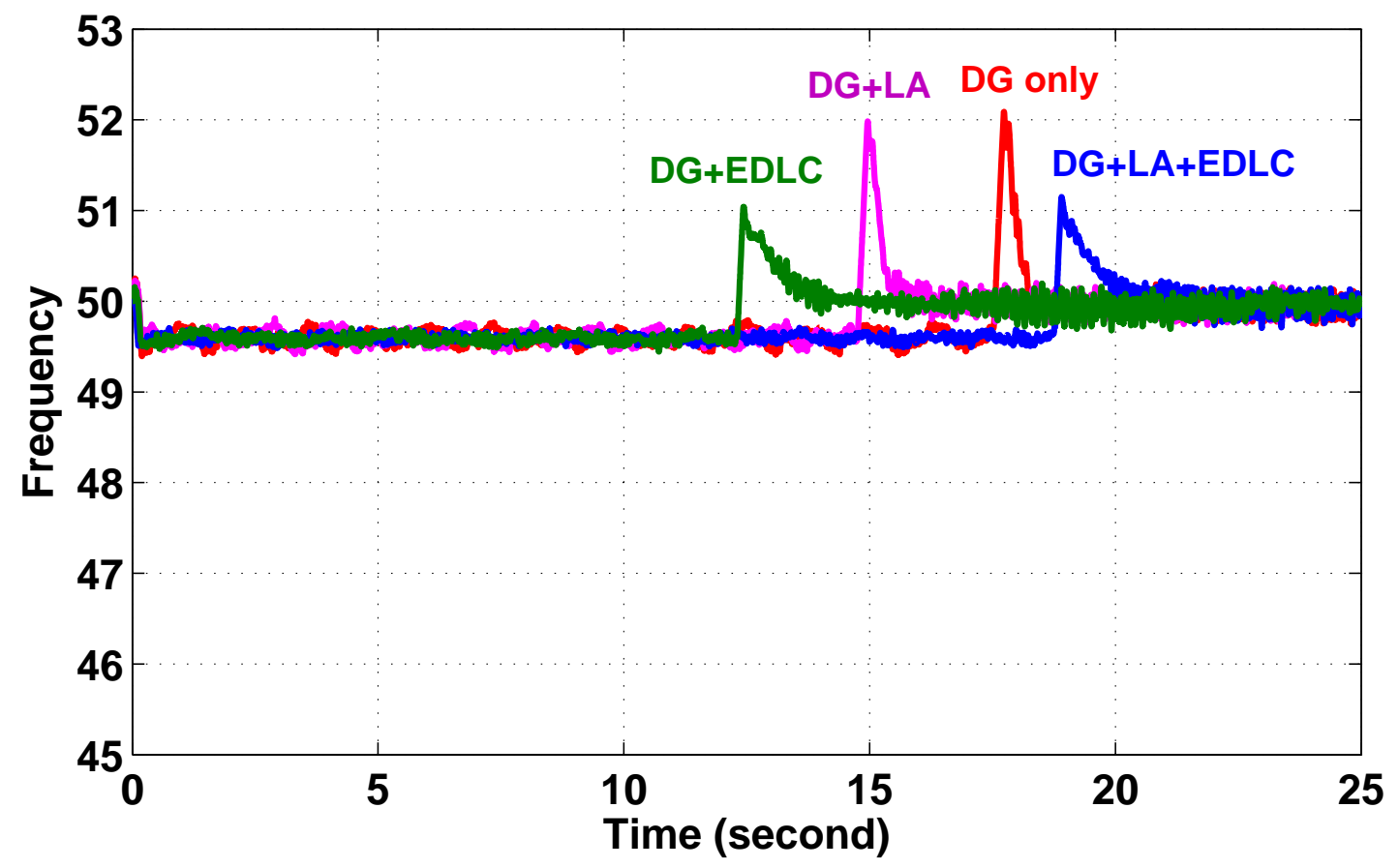

Figure 12. Experimental result showing microgrid frequency with and without storage during load step down from $150 \mathrm{~kW}, 50 \mathrm{kVAr}$ to $50 \mathrm{~kW}, 0 \mathrm{kVAr}$.

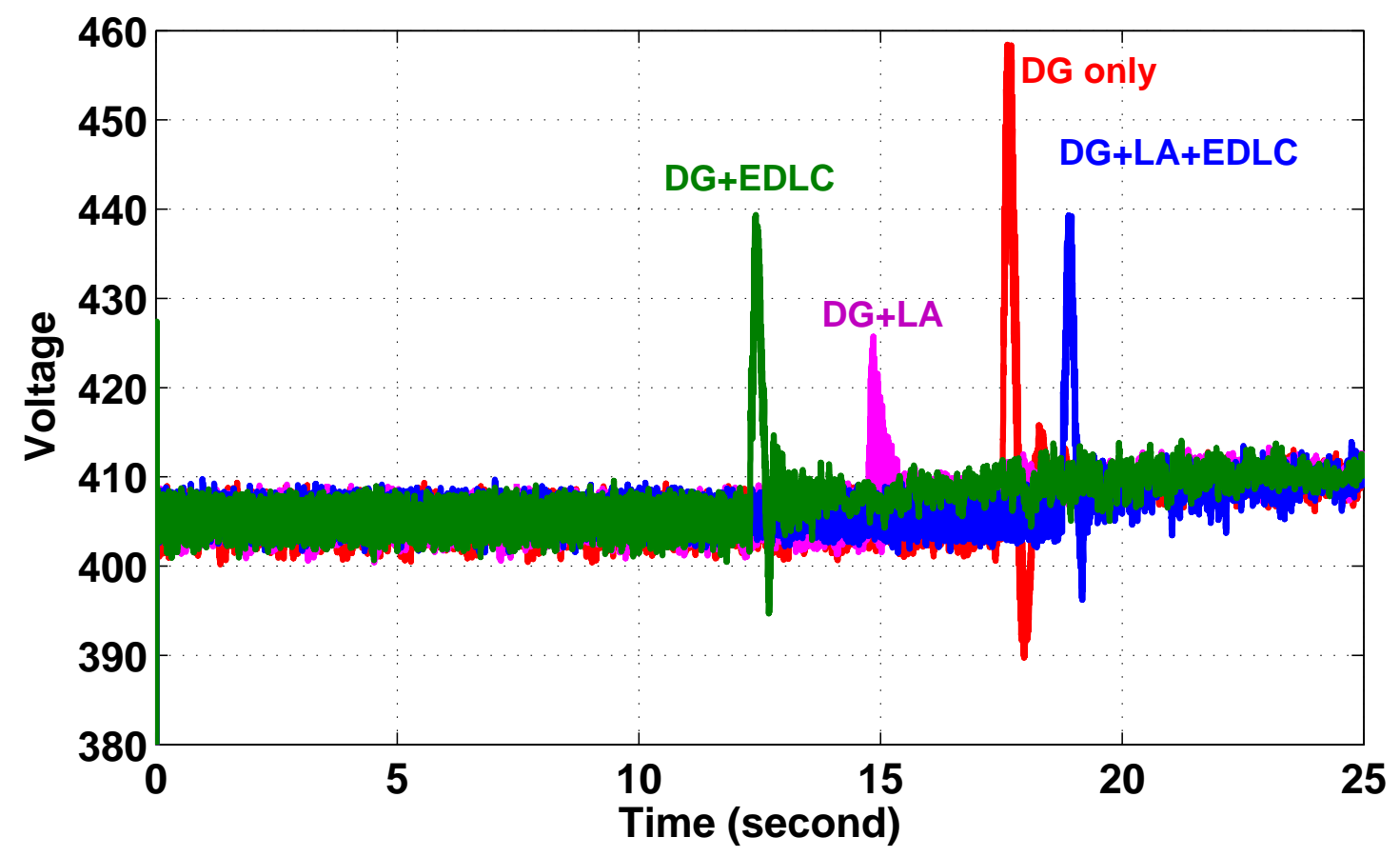

Figure 13. Experimental result showing microgrid voltage with and without storage during load step down from $150 \mathrm{~kW}, 50 \mathrm{kVAr}$ to $50 \mathrm{~kW}, 0 \mathrm{kVAr}$. 
Table 3. Summary of frequency and voltage variation with and without storage during step load change.

\begin{tabular}{llcccc}
\hline Load Test & Parameter & DG only & DG1+LeadAcid & DG1+LA+EDLC1 & DG1+EDLC1 \\
\hline Step Up & Frequency & -4.23 to $1.82 \mathrm{~Hz}$ & $-1.03 \mathrm{~Hz}$ & $-1.19 \mathrm{~Hz}$ & $-1.26 \mathrm{~Hz}$ \\
Step Down & Frequency & $2.09 \mathrm{~Hz}$ & $1.94 \mathrm{~Hz}$ & $1.03 \mathrm{~Hz}$ & $1.04 \mathrm{~Hz}$ \\
Step Up & Voltage & 13.1 to $-62.6 \mathrm{~V}$ & $-14.5 \mathrm{~V}$ & 5.7 to $-20.0 \mathrm{~V}$ & 5.9 to $-23.1 \mathrm{~V}$ \\
Step Down & Voltage & 56.1 to $-12.2 \mathrm{~V}$ & $22 \mathrm{~V}$ & 34.3 to $-7.4 \mathrm{~V}$ & 34.7 to $-9.6 \mathrm{~V}$ \\
\hline
\end{tabular}

\subsection{Control of Distributed Generators}

In simple microgrids, generation sources are often located close to each other. However, as microgrids grow and proliferate around the world, the generation sources within the microgrid can become more distributed. For example, renewable generation sources such as wind sources can be located at one side of the microgrid while main generators are located at the other side. In addition, microgrids can eventually connect with one another for greater reliability and resilience where generation from one microgrid can supply to another in times of need. However, such distributed generation or interconnection between microgrids may cause certain issues to arise especially when the generation sources have different control strategies. In the following experiment, a simple case of 2 generators connected via a line impedance has been used to showcase some problems that may occur in such situations. Even though additional sources and loads could have been easily added to this case, it has been simplified to highlight potential problems in distributed generation systems.

This case study experimentally investigates the workability of different control strategies for distributed generators. In the experimental setup, a $200 \mathrm{~kW}$ diesel generator (DG1) is run with a $100 \mathrm{~kW}$ diesel generator (DG2) separated by a line impedance of $20+\mathrm{j} 33 \mathrm{~m} \Omega$ as shown in Figure 14. This line impedance is almost equivalent to $400 \mathrm{~m}$ line length. This setup emulates a possible distributed generation scenario where sources connect to each other via short lengths of cable or overhead line. An example of such scenarios can occur in college campus microgrids where generation and load centers are distributed across a geographical area.

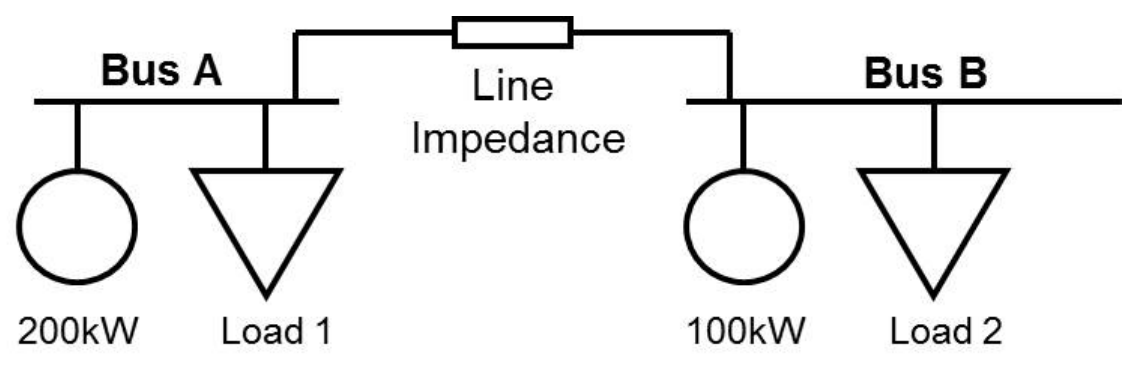

Figure 14. Setup of experiment.

In this experiment, two different control strategies have been examined. In the first control scheme, both DGs run in Power-frequency and Reactive Power-Voltage droop modes. The control block diagrams are shown in Figure 15. Loads 1 and 2 were then changed according to Table 4 . The active power, reactive power, voltages and frequency were then recorded. 


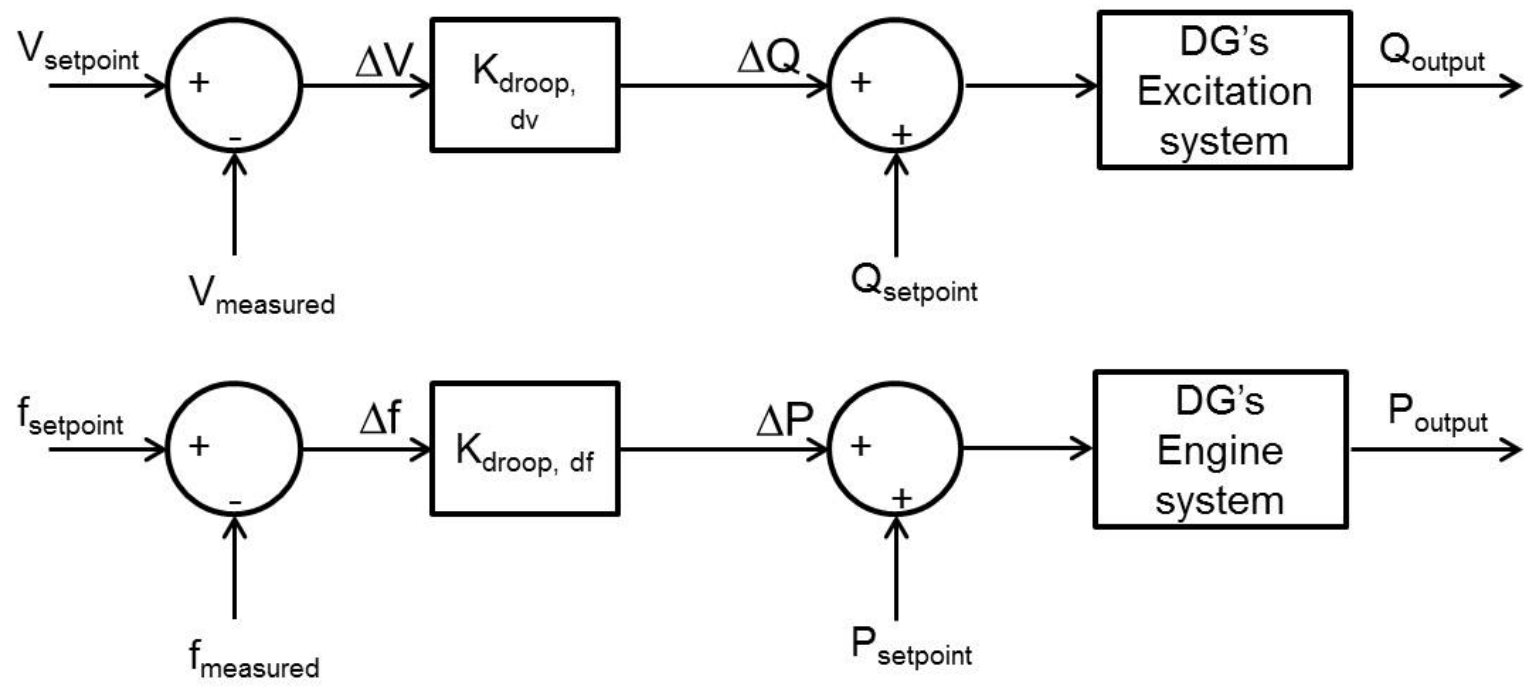

Figure 15. Droop control block diagrams for both DG1 and DG2.

Table 4. Load profile of loads 1 and 2.

\begin{tabular}{cccc}
\hline Number & Time $(\mathbf{s})$ & Load 1 (kW) & Load $2(\mathbf{k W})$ \\
\hline 1 & 0 & 50 & 150 \\
2 & 192 & 50 & 50 \\
3 & 560 & 150 & 50 \\
4 & 826 & 150 & 0 \\
\hline
\end{tabular}

Figures 16-18 show that the active power varies according to the frequency output while the reactive power varies according to the voltages on the respective buses. The voltages on the buses vary according to the power transfer from Bus A to Bus B and vice versa. It can be noted that there is slight frequency oscillation at a loading of $150 \mathrm{~kW}$ on bus $\mathrm{A}$. This can be due to the interaction between the two DG controllers. Another problem that can be noted is due to the voltage droop characteristics, $1 \mathrm{DG}$ would supply reactive power while the other consumes it. This increases the amount of losses in the line due to a higher current flow through the line.

In the second set of experiments, the control strategy has been changed to a Master-slave control scheme in which DG1 maintains the microgrid voltage and frequency to $415 \mathrm{~V}$ and $50 \mathrm{~Hz}$ respectively. DG2 controls the active power output to a setpoint of $80 \mathrm{~kW}$. The control block diagrams for DG1 and DG2 are shown in Figures 19 and 20 respectively. The load changes are similar to that in Table 4.

Figure 21 shows that the power outputs settle to steady-state in about 100-200 s. In comparison, the settling time for DGs in droop control is about 20-40 s. The slower response time in Master-Slave mode is due to the slow integral control of DG1 to bring the system voltage and frequency back to their normal setpoints. The frequency is brought back close to $50 \mathrm{~Hz}$ after each disturbance is shown in Figure 22 . Similarly, the voltage on bus A is maintained closed to $415 \mathrm{~V}$ after each disturbance (as shown in Figure 23). As in previous case, due to the voltage droop characteristics, DG2 consumes reactive power when the voltage is high. This causes DG1 to supply reactive power and hence increases the amount of losses in the line due to a higher current flow through the line. These experiments demonstrate the 
functionality of EPGC in facilitating testing of grid-related equipment with realistic power magnitudes. It also allows experimental testing of different control strategies and investigation into practical problems that may not be apparent in computer simulated environment.

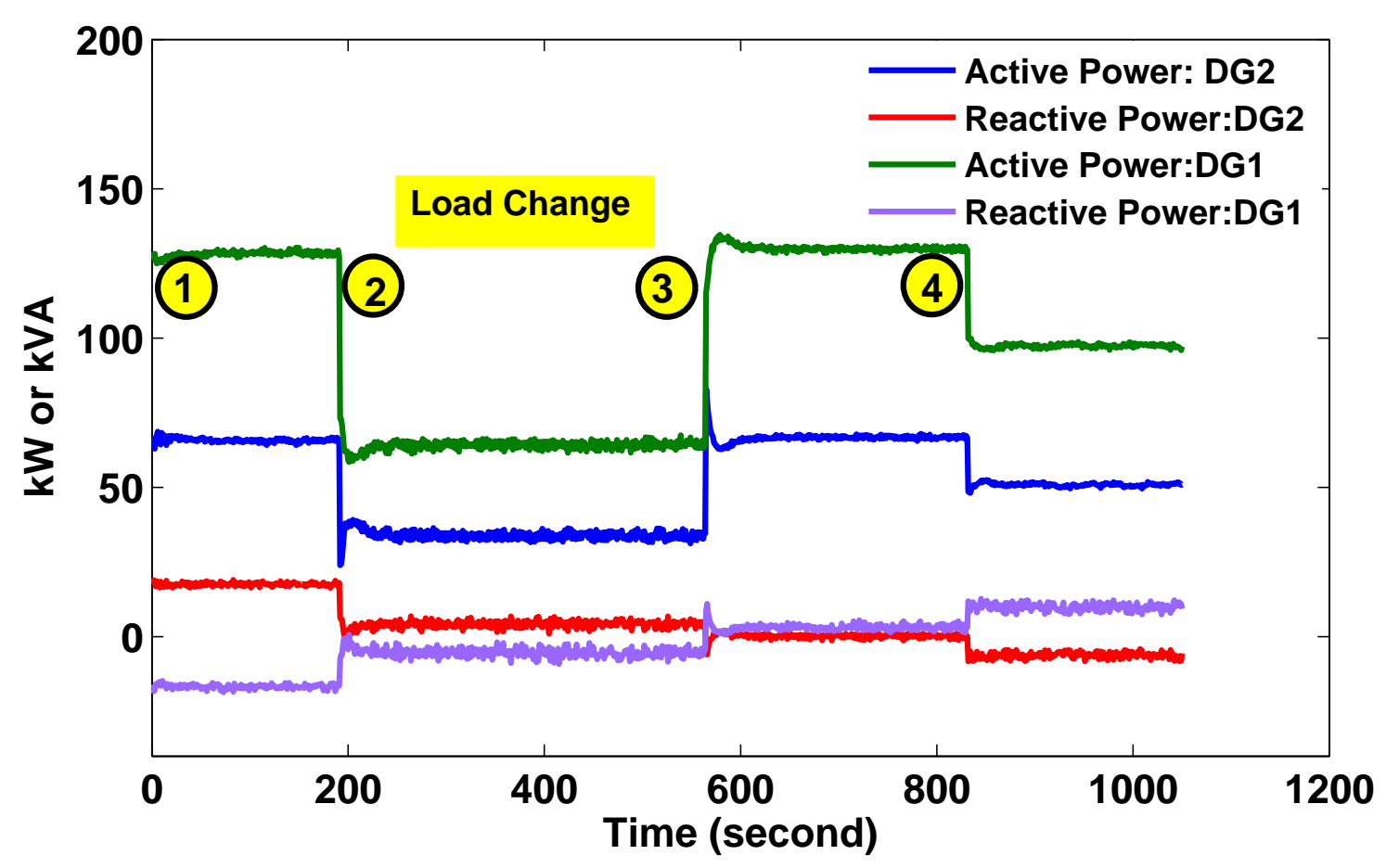

Figure 16. Active and Reactive Power Output of DGs in droop control.

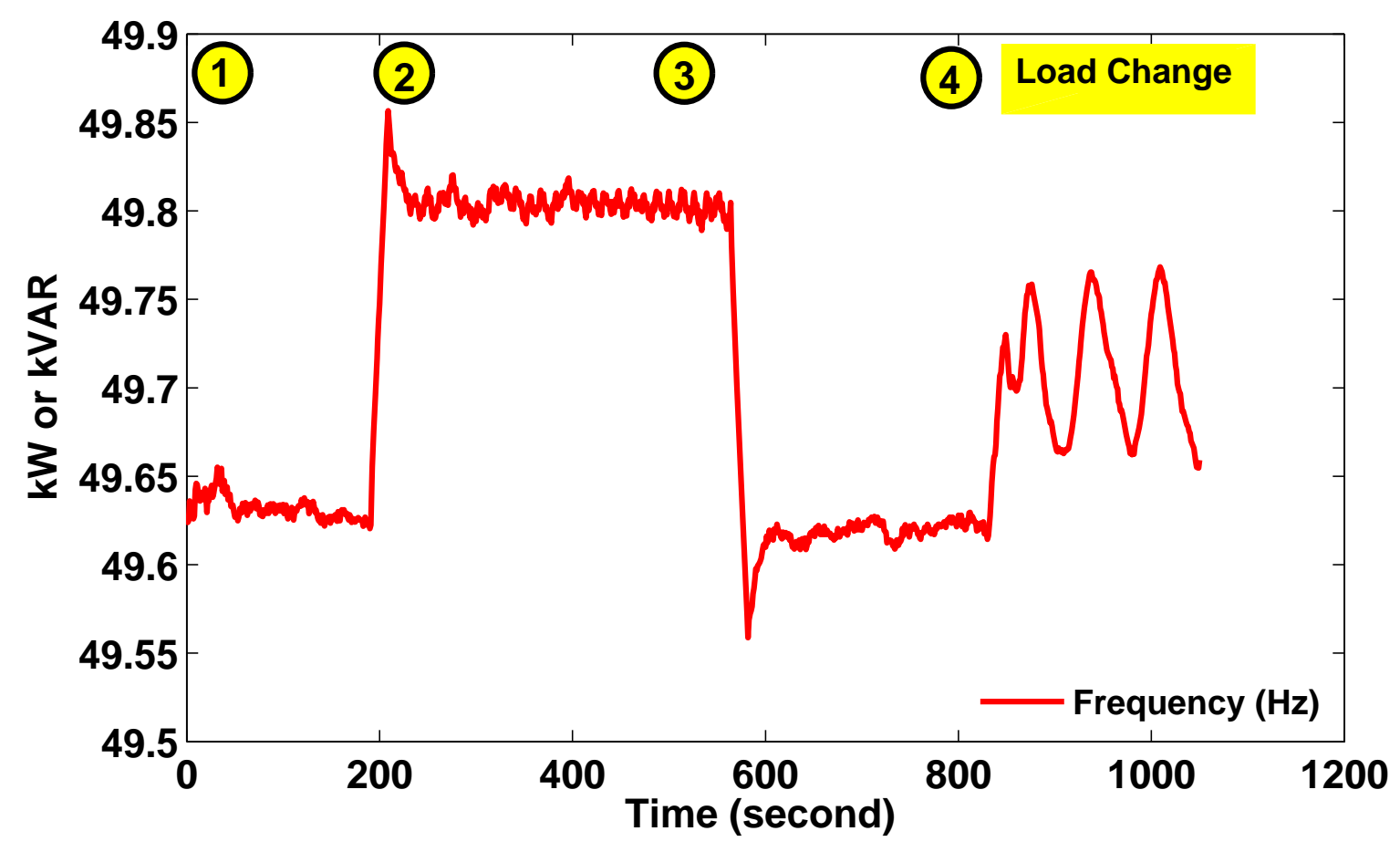

Figure 17. Frequency of DGs in droop mode. 


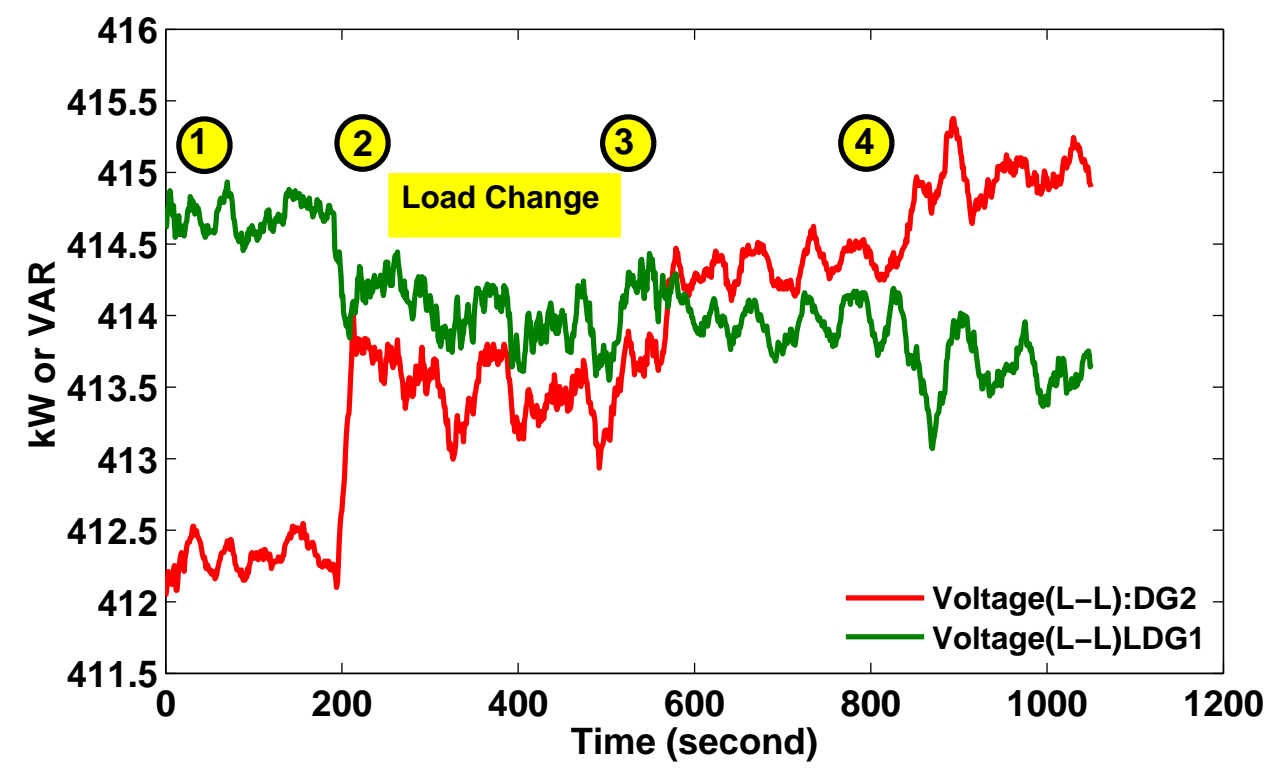

Figure 18. Voltages of DGs in droop mode.
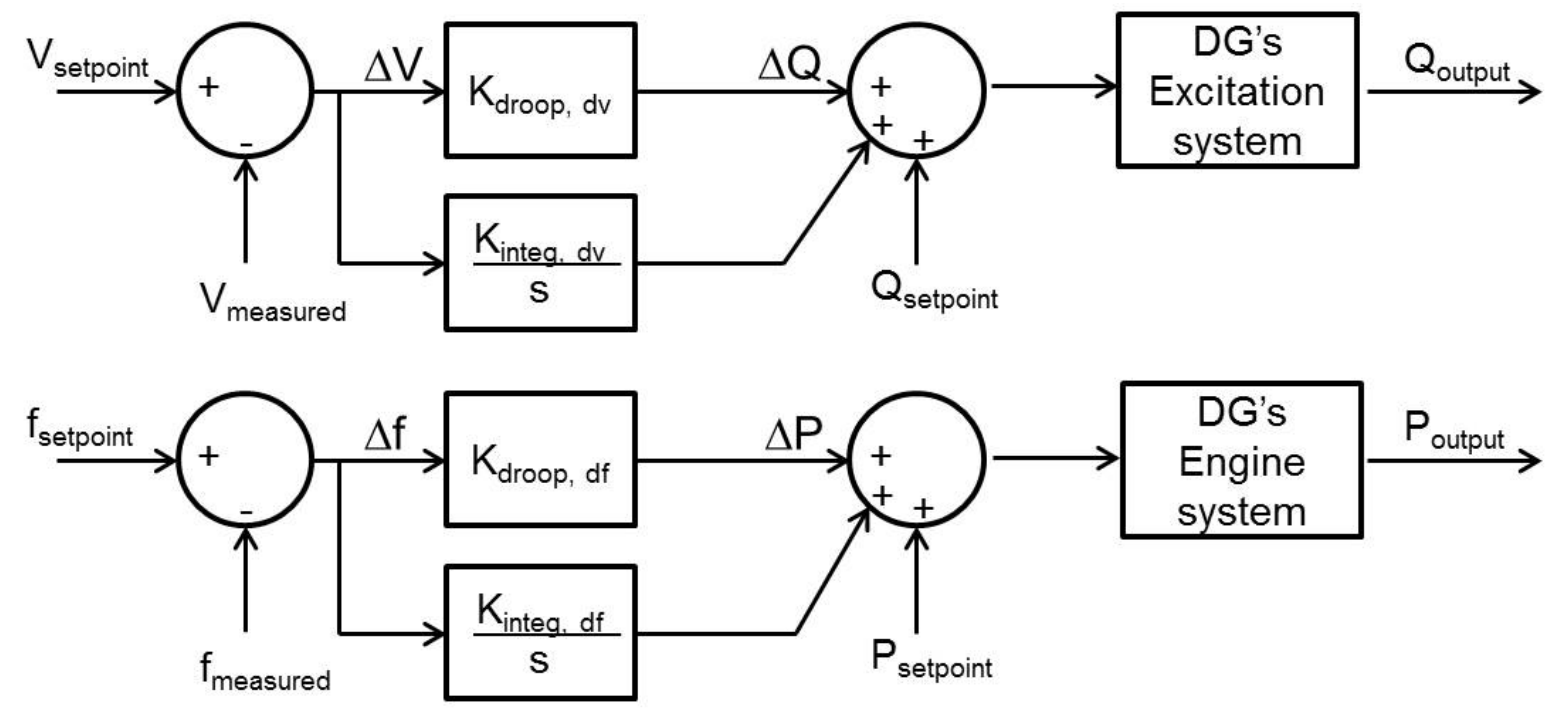

Figure 19. Control block diagrams for DG1.

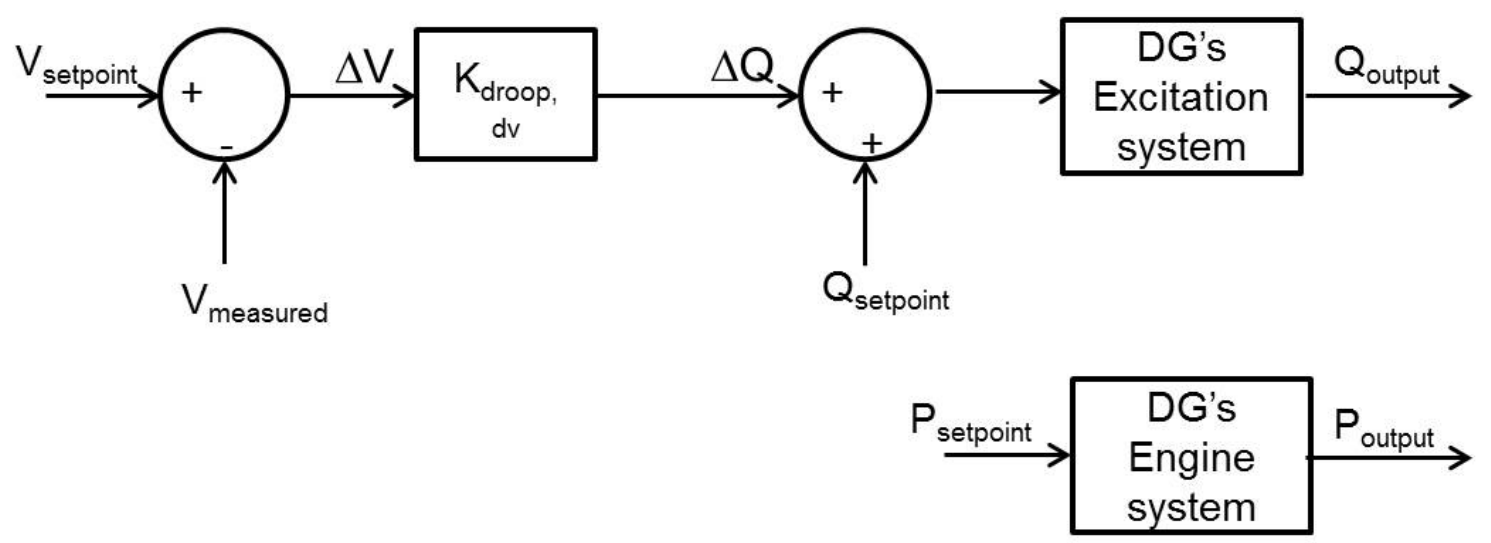

Figure 20. Control block diagrams for DG2. 


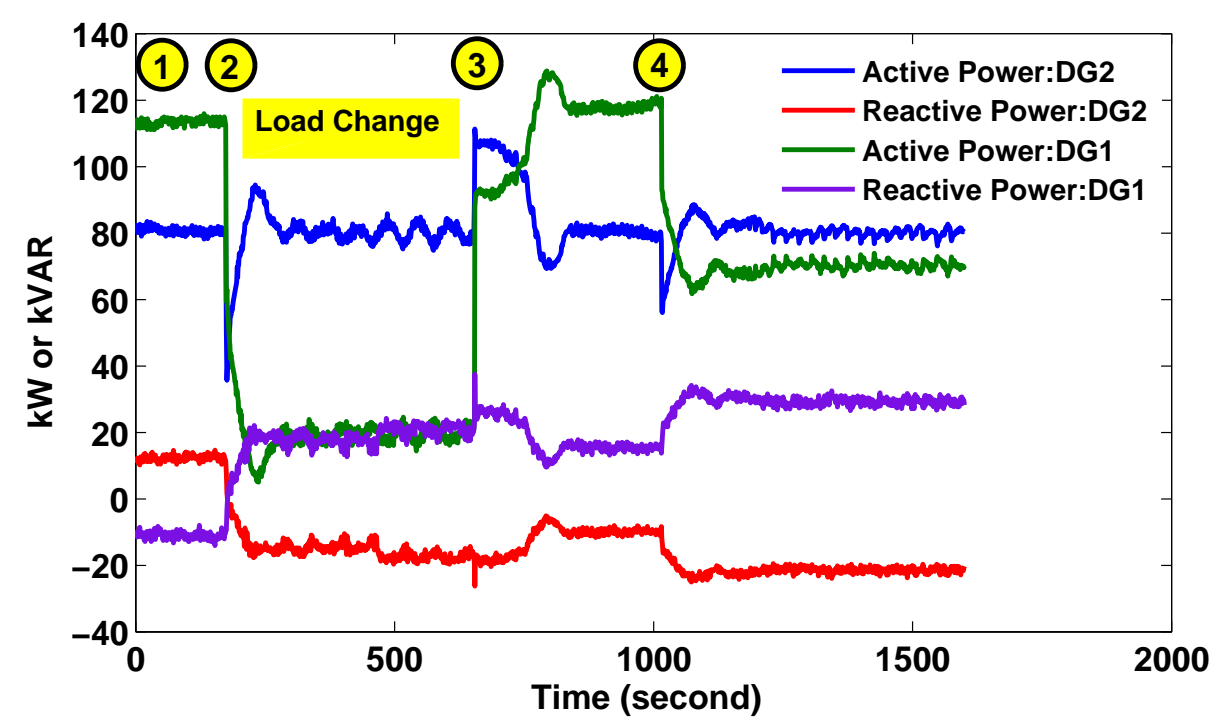

Figure 21. Active and Reactive Power Output of DGs in Master-Slave Control.

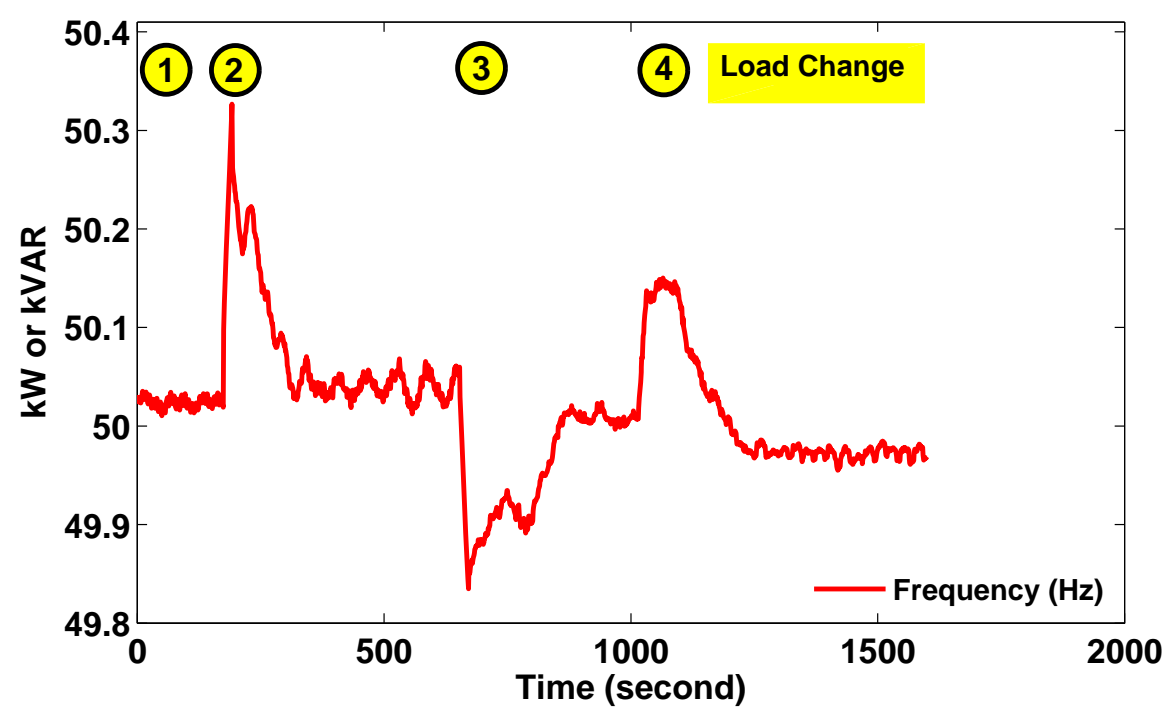

Figure 22. Frequency of DGs in Master-Slave Control.

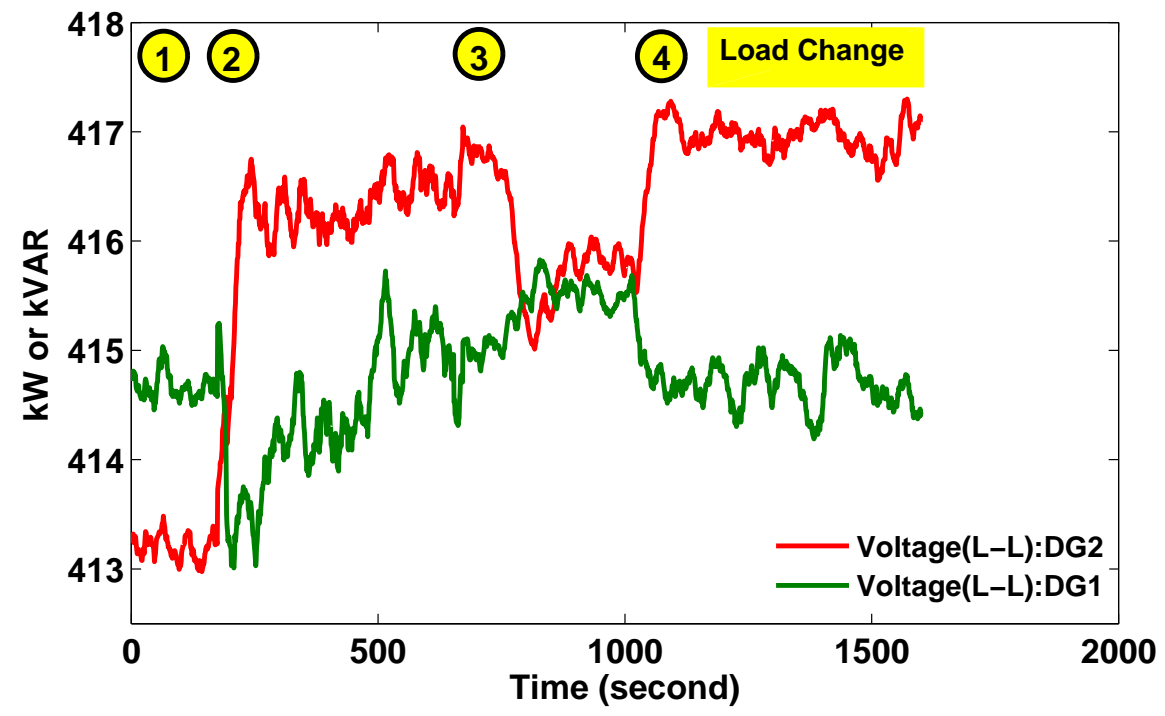

Figure 23. Voltages of DGs in Master-Slave Control. 


\subsection{Energy Efficiency of Integrated Thermal Grid in Microgrid}

An electrical microgrid integrated with thermal grid are noticeable to achieve high efficiency in the range of $60 \%-85 \%$ at design condition depending on the type of thermal supply i.e., steam, hot water or chilled water [27]. During actual operation, diesel generators follow the electrical load, and any variation in the electrical load will influence the diesel generator operation, which in turn affects the exhaust gas properties and thermal grid performance. A detailed experiment and test is required to investigate the performance of the thermal grid at different part load conditions, which arise in the waste heat generation and thermal loads. This case study investigates the energy efficiency of a thermal grid at different part loads faced by thermal systems. Figure 24 shows the heat recovered from the exhaust gas of a $125 \mathrm{kVA}$ generator using a waste heat recovery system at constant hot water flow. The heat energy recovered is $75 \%$ to $85 \%$ at full load due to high exhaust flow and temperature. At part loads, the heat energy recovered declines all the way to $30 \%$ to $35 \%$.

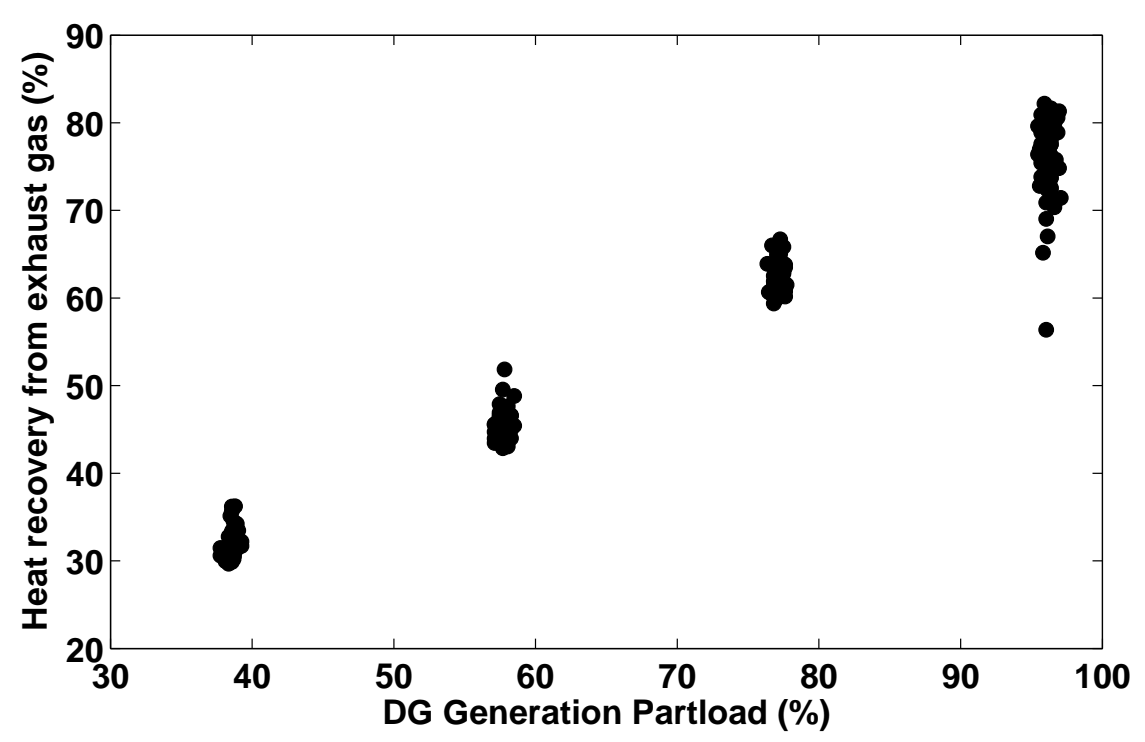

Figure 24. Heat recovered from the exhaust gas at different part loads of diesel generator.

The temperature of hot water generated by WHRS is at around 70 to $90{ }^{\circ} \mathrm{C}$ which is more suitable for cleaning and cooking purposes. Hot water can also be used to generate chilled water to support air conditioning purpose. By exploiting thermal storage, the excess hot water is stored and used to peak shaving, shifting operation and during unavailability of exhaust gas conditions. Figure 25 shows the heat availability in the thermal storage, the heat input to the absorption chiller and the cooling capacity generated by the chiller. The heat availability in thermal storage decreases with time because of supplying the hot water to the absorption chiller. The area of heat input and cooling capacity curves shows $30 \%-50 \%$ of heat input is converted to cooling capacity in the chilled water to support air conditioning loads. The range $30 \%-50 \%$ is in agreement for the single-effect hot water driven chiller at part load conditions [29]. This four cubic meter thermal storage can support chiller operation for more than an hour without WHRS operation. However, the cooling capacity generation is reduced due to a decrease in the heat capacity and heat input. 


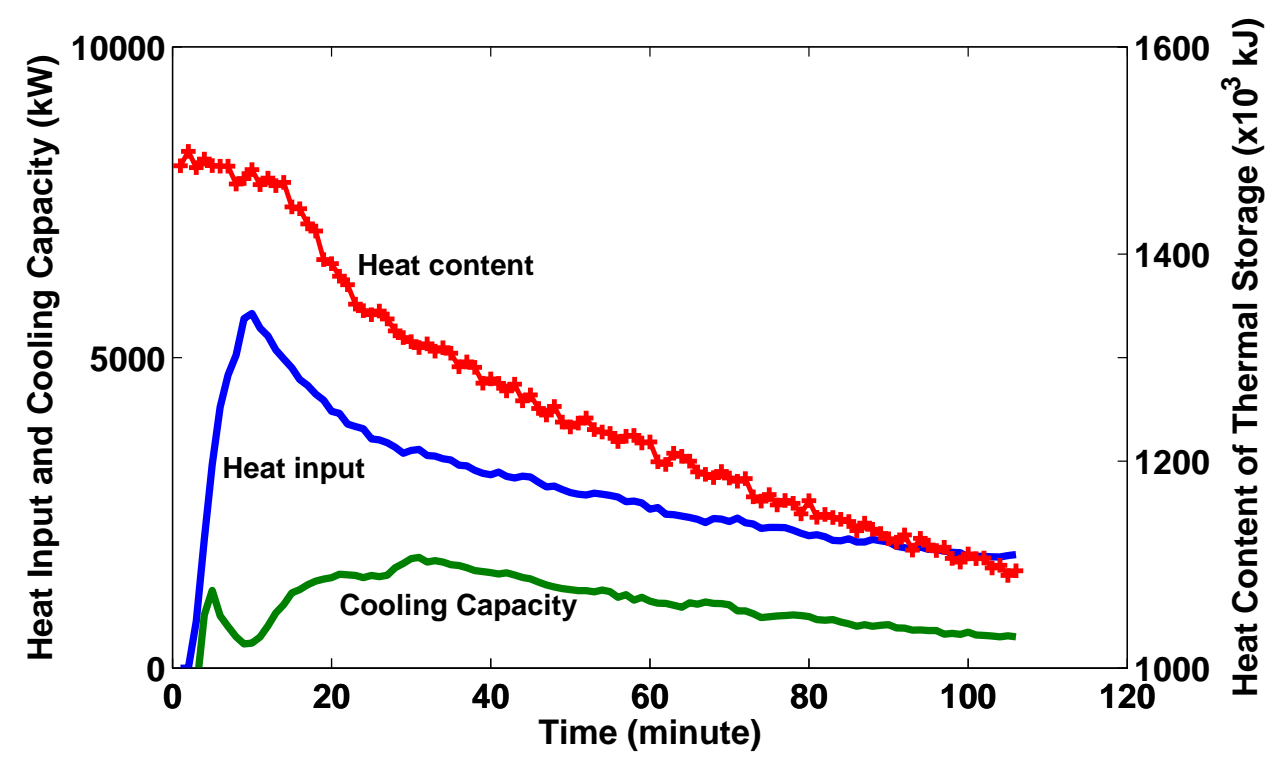

Figure 25. Cooling capacity generation and hot water temperature in the thermal storage.

The performance of the absorption chiller is influenced by the hot water, cooling water and chilled water inlet temperature and flow [30]. At rated condition, the hot water, cooling water and chilled water requirement is $90,29.5$ and $12{ }^{\circ} \mathrm{C}$. Any variation in the inlet temperature or flow due to generator operation, thermal loads and weather will affect the chiller performance. Figure 26 shows the performance of the chiller with the variation in the hot water inlet temperature at constant flow. The decrease in the hot water temperature from the design condition affects the efficiency of the chiller. Similarly chiller efficiency deteriorates when chilled water inlet temperature decreases or cooling water inlet temperature increases from the design value.

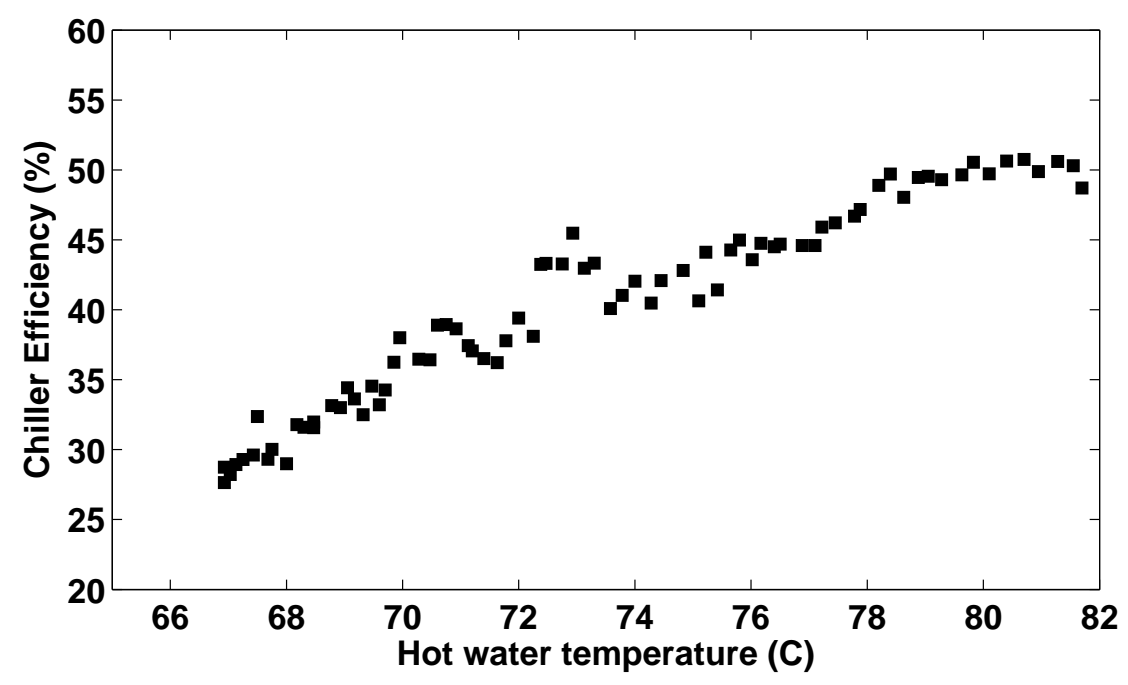

Figure 26. Chiller Efficiency as Coefficient of performance.

Figures 24-26 confirm that the performance of thermal systems is significantly influenced by the generators, thermal storage, chiller operation and thermal loads. The operational decisions are the key to achieve optimized performance and suppress performance deterioration. An advanced real-time 
optimized control is developed and implemented to derive optimized operational decisions every 10 to $30 \mathrm{~min}$ based on the thermal grid variables, predicted thermal load and weather condition. This advanced control is a remote system connected to the thermal grid energy management system to read the thermal grid variables and write the control decisions respectively.

The developed control system takes the (i) exhaust gas properties, (ii) hot water, chilled water and cooling water temperature and (iii) weather properties as inputs from the thermal grid energy management system and optimizes the thermal grid performance with respect to kWRT (as shown in Equation (5)). The optimized operational decisions derived are flowrate of hot water, chilled water and cooling water, and the air flow in cooling tower. These decisions are implemented in the testing facility by revising the corresponding setpoints of variable speed drives of hot water pump, chilled water pump, cooling water pump and cooling tower fan. The thermal grid performance is described in (Equation (5)) as kWRT which is the ratio of power consumption to generate one refrigeration ton of cooling capacity. The power consumption refers to the sum of power consumed by the chiller $\left(\mathrm{P}_{C H}\right)$, cooling tower $\left(\mathrm{P}_{C T}\right)$ and the pumps in hot, chilled and cooling water circuits $\left(\mathrm{P}_{h w}, \mathrm{P}_{c h w}, \mathrm{P}_{c w}\right)$. The verified thermodynamic model of thermal grid is used in the optimized control to generate the operational decisions.

$$
\begin{aligned}
\text { Min }: k W R T & =\frac{\text { Power consumed }(k W)}{\text { cooling capacity generated }(R T)} \\
k W R T & =\frac{\sum_{i=h w, c h w, c w, C H, C T} P_{i}}{m_{c h w} C_{p} \triangle T}
\end{aligned}
$$

Figure 27 shows the energy efficiency of thermal grid, a high efficiency system achieves a smaller value of $\mathrm{kW}$ per ton to generate cooling capacity. Figure 27 shows the preliminary results of thermal grid performance which show that optimized control scheme have performance benefits of up to $20 \%$ at part load conditions. The performance benefits are projected up to $40 \%$ in large capacity system in the range of 500 KVA diesel generators [28]. This thermal grid facility with adequate instrumentation allows system level analysis and validate new optimized control algorithms.

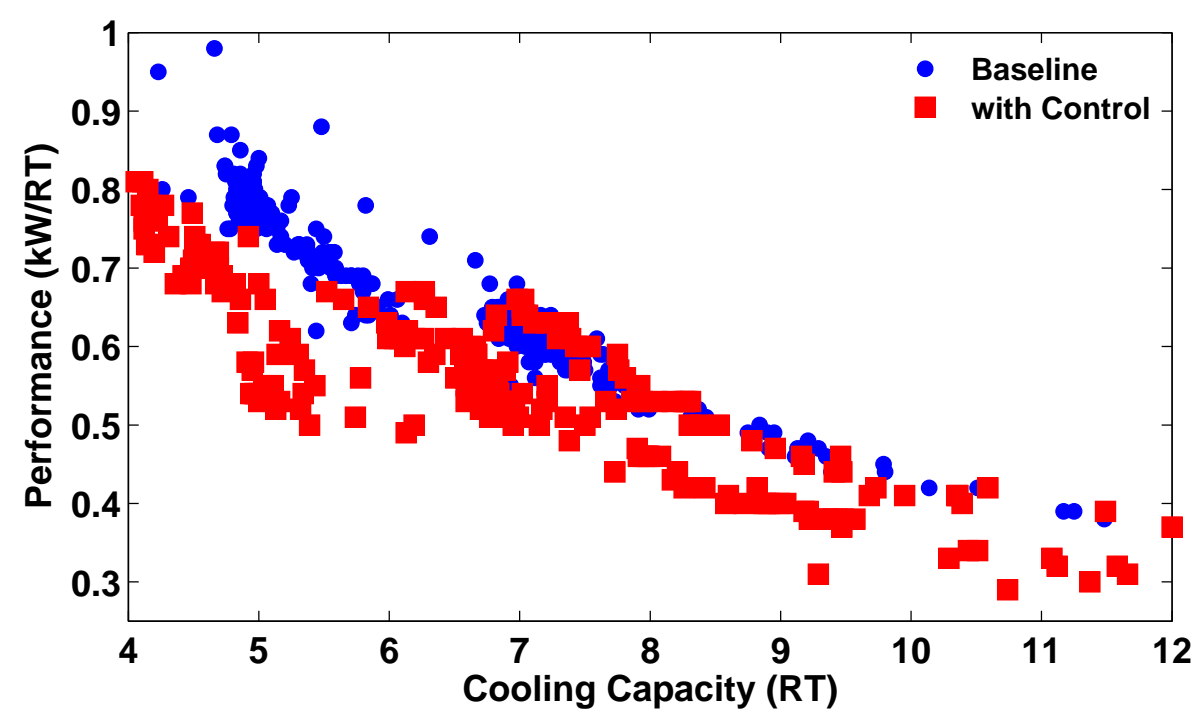

Figure 27. Thermal grid performance with baseline operation and optimized controller. 


\section{Conclusions}

This paper presented an overview of EPGC's microgrid facility which has flexible grid architecture and variety of emulators and distributed energy sources. The facility allows testing and development of microgrid control strategies in different grid configurations and modes of operation. In addition, the facility also has a thermal grid, which allows for experimentation of integrated electrical-thermal systems to optimise and achieve higher energy efficiency and cost benefits. The functionalities of the microgrid test facility have been highlighted through selected case studies. The testing of DG and future microgrid technologies with realistic power magnitudes and accordance with the international standards make this test facility a unique and key enabler for the widespread adoption of the microgrid. The experimental verification provides higher confidence in the technology which is surely limited in the computer simulation environment. The influence of physical limits in the electrical and thermal systems and their response time can be precisely observed in the experiments, which is not evident in software models and simulators.

\section{Author Contributions}

Sundar Raj Thangavelu: Developed the optimized control algorithm for thermal grid and validated the performance provided in Section 3.5. Inam Ullah Nutkani: Contributed the experiment and analysis presented in Sections 3.1 to 3.3. Chia Meng Hwee: Contributed the experiments and analysis presented in Section 3.4. Aung Myat: Designed the thermal grid and conducted experiments discussed in Section 3.5. Ashwin Khambadkone: Scoped the experiments and framed this article structure. All authors contributed in scoping and drafting relevant sections of this article.

\section{Conflicts of Interest}

The authors declare no conflict of interest.

\section{References}

1. Microgrids-Benefits, Models, Barriers and Suggested Policy Initiatives for the Commonwealth of Massachusetts; KEMA Inc.: Burlington, MA, USA, 2014.

2. Ackermann, T.; Andersson, G.; Soder, L. Distributed generation: A definition. Electr. Power Syst. Res. 2001, 57, 195-204.

3. Hossain, E.; Kabalci, E.; Bayindir, R.; Perez, R. Microgrid testbeds around the world: State of art. Energy Convers. Manag. 2014, 86, 132-153.

4. Ramazan, B.; Eklas, H.; Erdal, B.E.K. Microgrid Facility at European Union. In Proceedings of the 3rd International Conference on Renewable Energy Research and Applications, Milwakuee, WI, USA, 19-22 October 2014.

5. Morozumi, S. Micro-grid Demonstration Projects in Japan. In Proceedings of the Power Conversion Conference, Nagoya, Japan, 2-5 April 2007; pp. 635-642.

6. International Microgrid Assessment: Governance, INcentives, and Experience (IMAGINE); European Council for an Energy-Efficient Economy: Hyeres, France, 2013. 
7. Microgrid Deployment Tracker. Available online: https://www.navigantresearch.com/research/ microgrid-deployment-tracker-2q15 (accessed on 8 September 2015).

8. Christopher, V.D.E. Microgrids: A Regulatory Perspective. Available online: http://www.cpuc.ca. gov/NR/rdonlyres/01ECA296-5E7F-4C23-8570-1EFF2DC0F278/0/PPDMicrogridPaper414.pdf (accessed on 7 September 2015)

9. IEEE Standard 1547-2003. IEEE Standard for Interconnecting Distributed Resources with Electric Power Systems; IEEE: Piscataway, NJ, USA, 2003; pp. 1-28.

10. IEEE Standard 1547.4-2011. IEEE Guide for Design, Operation, and Integration of Distributed Resource Island Systems with Electric Power Systems; IEEE: Piscataway, NJ, USA, 2011.

11. Report on standards and grid code requirements applied to LV DG devices, Available online: http://www.microgrids.eu/documents/654.pdf (accessed on 7 September 2015).

12. Boemer, J.; Burges, K.; Kumm, T. Compliance with Technical Codes Turns into Precondition for Support and System Services Bonus for Wind Power Plants in Germany. In Proceedings of the 2009 IEEE Bucharest PowerTech, Bucharest, Rumania, 2009; pp. 1-8.

13. Brooks, D.; Patel, M. Panel: Standards Amp, Interconnection Requirements for Wind and Solar Generation NERC Integrating Variable Generation Task Force. In Proceedings of the 2010 IEEE PES Transmission and Distribution Conference and Exposition, New Orleans, LA, USA, 19-22 April 2010.

14. Design and operational Recommendations on Grid Connection of PV Hybrid Mini-Grids; International Energy Agency: Paris, France, 2011.

15. Standard Code: JEAC 9701-2012. Grid Interconnection Code; Japan Electric Association: Tokyo, Japan, 2012.

16. Technical Requirements Guideline of Grid interconnection to Secure Electricity Quality; Ministry of Economy, Trade and Industry (METI): Tokyo, Japan, 2013.

17. Kish, G. Addressing Future Grid Requirements for Distributed Energy Resources. Master's Thesis, University of Toronto, Toronto, ON, Canada, 2011.

18. Kish, G.; Lehn, P. Microgrid Design Considerations for Next Generation Grid Codes. In Proceedings of the 2012 IEEE Power and Energy Society General Meeting, San Diego, CA, USA, 22-26 July 2012; pp. 1-8.

19. El-Hawary, M.E. The Smart Grid-State-of-the-Art and Future Trends. Electr. Power Compon. Syst. 2014, 42, 239-250.

20. Sharma, G.; Xie, L.; Kumar, P.R. On the Optimality of De-Synchronized Demand Response with Stochastic Renewables and Inertial Thermal Loads. In Proceedings of the 2013 IEEE 52nd Annual Conference on Decision and Control, Firenze, Italy, 10-13 December 2013; pp. 6292-6297.

21. Sanaye, S.; Sarrafi, A. Optimization of combined cooling, heating and power generation by a solar system. Renew. Eenergy 2015, 80, 699-712.

22. Diesel Generators. Available online: http://https://www.fgwilson.com/ (accessed on 7 September 2015).

23. High Performance Solar Modules, REC Peak Energy Series. Available online: http://www. recgroup.com (accessed on 7 September 2015). 
24. Murphy, M.D.; O’Mahony, M.J.; Upton, J. Comparison of control systems for the optimisation of ice storage in a dynamic real time electricity pricing environment. Appl. Energy 2015, 149, 392-403.

25. Bari, S.; Hossain, S.N. Waste heat recovery from a diesel engine using shell and tube heat exchanger. Appl. Therm. Eng. 2013, 61, 355-363.

26. CRC Handbook of Energy Efficiency; Frank Krieth, R.E.W., Ed.; CRC Press: Boca Raton, FL, USA, 1996.

27. Mohan, G.; Dahal, S.; Kumar, U.; Martin, A.; Kayal, H. Development of natural gas fired combined cycle plant for tri-generation of power, cooling and clean water using waste heat recovery: techno-economic analysis. Energies 2014, 7, 6358-6381.

28. Thermax Multi Energy Absorption Chillers for Small Scale Cogeneration Projects. Available online: http://www.districtenergy.org/assets/pdfs/2012CHP-Texas (accessed on 7 September 2015).

29. Thermax products, Absorption Systems, Absorption Chillers. Available online: http://www.thermaxglobal.com (accessed on 7 September 2015).

30. Prasartkaew, B. Performance Test of a Small Size LiBr- $\mathrm{H}_{2} \mathrm{O}$ Absorption Chiller. Energy Procedia 2014, 56, 487-497.

(C) 2015 by the authors; licensee MDPI, Basel, Switzerland. This article is an open access article distributed under the terms and conditions of the Creative Commons Attribution license (http://creativecommons.org/licenses/by/4.0/). 